\title{
NRLMSISE-00 EMPIRICAL MODEL OF THE ATMOSPHERE: STATISTICAL COMPARISONS $\Lambda$ ND SCIENTIFIC ISSUES
}

\author{
J. M. Picone, A. E. Hedin' ${ }^{1}$, and D. P. Drob \\ E. O. Hulburt Center for Space Research \\ Naval Research Laboratory \\ Washington, DC 20375
}

\author{
A. C. Aikin \\ Laboratory for Atmospheres \\ NASA Goddard Space Flight Center \\ Greenbelt, Maryland 20771
}

Submitted to:

Journal of Geophysical Research

December 2001

1 Universities Space Research Association, Washington, DC 20024-4703 


\begin{abstract}
The new NRLMSISE-00 model and the associated NRLMSIS database now include the following data: (1) total mass density from satellite accelerometers and from orbit determination, including the Jacchia and Barlier data; (2) temperature from incoherent scatter radar, and; (3) molecular oxygen number density, $\left[\mathrm{O}_{2}\right]$, from solar ultraviolet occultation aboard the Solar Maximum Mission (SMM). A new component, "anomalous oxygen," allows for appreciable $\mathrm{O}^{+}$and hot atomic oxygen contributions to the total mass density at high altitudes and applies primarily to drag estimation above $500 \mathrm{~km}$. Extensive tables compare our entire database to the NRLMSISE-00, MSISE-90, and Jacchia-70 models for different altitude bands and levels of geomagnetic activity. We also investigate scientific issues related to the new data sets in the NRLMSIS database. Especially noteworthy is the solar activity dependence of the Jacchia data, with which we investigate a large $\mathrm{O}^{+}$contribution to the total mass density under the combination of summer, low solar activity, high latitudes, and high altitudes. Under these conditions, except at very low solar activity, the Jacchia data and the Jacchia-70 model indeed show a significantly higher total mass density than does MSISE-90. However, under the corresponding winter conditions, the MSIS-class models represent a noticeable improvement relative to Jacchia- 70 over a wide range of $F_{10.7}$. Considering the two regimes together, NRLMSISE-00 achieves an improvement over both MSISE- 90 and Jacchia- 70 by incorporating advantages of each.
\end{abstract}




\section{Introduction}

The NRLMSISE-00 empirical model of thermospheric composition and temperature is now available for access and use by the scientific and operational communities (Appendex, subsection A.4). This paper compares the new model to the standard scientific (MSISE-90 [Hedin, 1991]) and operational (Jacchia-70 [Jacchia, 1970]) empirical models presenty in use, through statistical comparison with the previous MSIS database and with the newly added data sets that make NRIMSISE-00 unique. We then address scientific issues related to the newly added data.

This milestone fulfills our initial goal of preserving and continuing the line of MSIS-class models. Enpirical models of the thermosphere and upper mesosphere are an indispensable tool used by the operational and upper atmospheric research communities for data analysis, initialization of derailed physics-based models, and mission and instrument design. For over a decade, the madels of choice among scientists have been the Mass Spectrometer - Incoherent Scatter Radar (MSIS-class) models of uppar atmospheric composition and temperature: MSIS-86 [Hedin, 1987], which ranges upward from $90 \mathrm{~km}$, and MSISE-90, which extends from the ground to the exobase. Some research communities continue to use the CRA-86 climatology, which consists of two overlapping specifications: tables generated from MSIS-86 for the thermosphere (altitude $z>100 \mathrm{~km}$; htp://nssde.gsfe.nasa.gov/space/model/atmos/cospar2.html)) and tables based on averages of global data compilations for the mesosphere and below ( $z<120$ km; http://nssdc.gsfc.nasa.gov/space/modelatmos/cosparl.html). Operational communities use the Jacchia-class models or in some cases, the extremely limited US Standard Atmosphere (http://nssdc.gsfc.nasa.gov/space/model/atmoshs_standard.html). The database underlying operational Jacchia models ( 1970 and earlier) consisis of total mass density derived from orbital decay of objects which flew during the 1961-70. Past MSIS-class models derived from over twodecades of data on composition, temperanure, and total mass density, rather than from orbital dynamics.

For estimating total mass density, the NRLMSISE-00 model and its underlying database are at least comparable to the Jacchia-class models, given the inclusion of numerous orbital drag (F. Barlier, private communication to A. Hedin) and accelerometer data sets (F. Marcos, private communication). A noteworthy addition to the database is the actual orbital decay data on which 
the Jacchia models are primarily based. The model also incorporatcs recent daca on temperature and molecular oxygen number density, $\left[\mathrm{O}_{2}\right]$. The new data sets are extensive in size, sparial range and the time period covered and represent significant departures from the MSIS database used to produce previous generations of the model.

This upgrade is important because the MSIS and Jacchia models do not depend on calendar year and cannot directly track any gradual changes in the atmosphere due to anthropogenic or solar influences. The only way in which empirical models can maintain currency with the recent state of the atmosphere is by continually adding recent clata to the database and then modifying the paramerer set. In addition, instrumentation and data processing methods have improved and have become more diverse, potentially allowing the addition of higher order terms and reducing the uncertainty of the model coeificients. To accommodate new data, the formulation of the model and the methodology for generating it have become more robust (Appendix).

One change is paricularly worhy of mention. The inclusion of drag data in a neutral armospheric model has required us to account explicitly for high altitude $\mathrm{O}^{+}$and hot atomic oxygen components, which might contribute appreciably lo drag under some conditions (Section 4.1). As a result, the NRLMSIS formulation now explicitly includes a component, called "anomalous oxygen," to accouft the contribution of these species to satellite drag at high altirudes and permits the user to compute both the "thermospheric mass density" (or "total neutral mass density") provided by past generations of MSIS and an "effective" mass density, which denoies the sum of the themospheric mass density and the anomalous oxygen contribution at altitudes near the exobase.

To introduce the new model, Section 2 describes the newly added data sets and their relationship to the previous database. Section 3 presents statistical comparisons of NRLMSISE00, MSISE-90, and Jacchia-70 with the NRLMSIS database. The statistical tables significantly augment a previous report on drag and accelerometer data [Hedin, 1988]. Section 4 discusses important scientific issues related to the new data and madel, and Section 5 discusses our conclusions regarding NRIMSISE-00 and the direction of future development. The Appendix summarizes the formulation, generation, and access of the new model and addresses the use of orbital drag and accelerometer data to generate NRLMSISE-00. 


\section{The NRLMSIS database and model}

\section{2.l. Relationship to past models}

NRLMSISE-00 retains the calling sequence and arguments of MSISE-90 and earlier $\rightarrow$ MSIS models in the remainder of the paper, we will often exclude the designation "E-OO" for the sake of breviry. One can usefully intepret the NRLMSIS nodel as a flexible, semi-empirica] view of its extensive underlying database. That is, the model takes statistical variability into account while interpolating among, or extrapolating, the underlying data sets to estimate composition and temperature for times. geophysical conditions, and locations not covered specifically by the database. As with earlier versions of the MSIS-class models, the NRIMSIS database includes ground-, rocket-, and satellite-based measurements. The data underlying MSISE-90 cover the period $1965-83$ and derive from incoherent scatter radar (ISR), mass spectrometer, solar ultraviolet (UV) occultation, pressure gauge, falling sphere, and grenade detonations. Until now, the database has not included either drag measurements, on which the Jacchia models were based, or satellite-bone accelerometer data. The new NRIMSIS upgrade includes those data sets.

Both the MSIS and Jacchia models are sensitive to the level of geomagnetic activity and provide an estimate of the average upper atmospheric state under geomagnetic stom conditions. However, at high latitudes and high geomagnetic activity, the databases are sparse, and as statistical averages the models do not capture the local structure and shorter time scales associated with any particular storm. The NRIMSISE-00 model remains a statistical average. but the database now contains more data covering extremes of location and forcing.

\subsection{Expanded database}

The most important upgrade has been the addicion of recent dara sets and new categories of data to augment the NRLMSIS database and model:

(a) Satellite drag [Jacchia, 1970; Barlier, 1978; Hedin, 1988]: orbit delermination (1961-1971);

(b) Accelerometer (Hedin, 1988; F. Marcos, private communication): Atmospheric Explorer (AE-C, D, E) MESA [Champion and Marcos, 1973], Air Force SETA [Rhoden et al., 2000], CACTUS [Boudon et al., 1979], San Marco-5 [Arduini et al., 1997]]; 
(c) Incoherent scatter radar (ISR) - exospheric temperature ( $\left.T_{c x}\right)$ : Millstone Hill (1981-97; $\checkmark$ [Buonsanto and Poblman, 1998]), Arecibo (1985-95; [Melendez-Alvira et al., 1998]

(d) ISR - Lower thermospheric temperature ( $\left.T_{10 w}\right)$ : Millstone Hill (1988-97; Goncharenko and Salah [1998].

(e) Solar Maximum Mission (SMM) $\mathrm{O}_{2}$ density data derived from occulcation of solar UV enissions [Aikin et al., 1993].

Ingesting the drag and accelerometer data on total mass density $(\rho)$ promises to remove a postulated deficiency of MSIS for orbital tracking applications. With the inclusion of the Jacchia data, the more exiensive and well-documented NRLMSIS database should equal or improve the statiscical predictions of $\rho$ and of drag over those of the Jacehia models. We expect to test this hypothesis by applying the model to operarional precision orbit determination and prediction [Knowles et al., 2001]. An inportant point is that the new data on total mass density also influence the model coefficients for both temperamre and composition. These differences should become apparent as NRLMSIS is compared to additional data sets.

The incoherent scatter iadar data directy influence the model temperature, which is the core of the MSIS formulation. Further, the new data cover an appreciable fraction of a solar cycle or more and are viral for both testing the existing models and producing new versions. The methods of processing ISR data have also undergone significant improvements over the last decade, increasing the quality of the inferred ionospheric properties [Gonzales and Sulzer, 1996]. This factor imparts high value to our new data sets.

The Millstone Hill data on lower thermospheric temperarure ( $\left.T_{\text {low }}\right)$ cover $100 \mathrm{~km} \leq z$ $\leq 130 \mathrm{~km}$ [Goncharenko and Salah, 1998]. In this regime, the neutral temperature is approximately equal to the ion temperature, so that extraction of the information is straightforward. These high quality data permit us to check and reinforce key MSIS temperature model parameters and ingertant in defining the model at the mesopause.

The SMM mission provided data on the molecular oxygen number density $\left[\mathrm{O}_{2}\right]$ over the altitude range $140-200 \mathrm{~km}$ and over a wide range of solar activity. Prior 10 SMM, direct measurements of $\left[\mathrm{O}_{2}\right]$ above $150 \mathrm{~km}$ were not available at high solar activity. The $S M M$ occultation measurements sugges: that dissociation may increase sufficiently to keep this density 
nearly constant at $200 \mathrm{~km}$ as solar activity increases [Kayser, 1980; Aikin et al, 1993]. These data are now part of the NRLMSIS database and will be important in determining dependence on the solar extreme ultraviolet (EUV) flux and on magnetic activity. As a result, the dara should be particularly useful in future analysis of better EUV proxies (e.g., Lean er al. [2001]). On the other hand, the longstanding conflict berween mass spectrometer and solar UV occultation measurements of themospheric [ $\left.\mathrm{O}_{2}\right]$ has had a profound effect on NRLMSIS, because the occultation data do not follow diffusive equilibrium, contradicting mass spectrometer data [Aikin et al., 1993]. At the same time, the latter could be biased toward high values by recombination of atomic oxygen within the instrument. As an example, the two sources disagree on average by a factor of two or more at $200 \mathrm{~km}$. The SMM dara set has therefore required alterations in the formulation of NRIMSIS (see Appendix) and has significantly influenced the dependence of $\left[\mathrm{O}_{2}\right.$ ] estimates on $\mathrm{F}_{10.7}$ (Secrion 4.2).

\section{Statistical comparisons of models to data}

A key component of this paper is the presentation of coarse statistical measures (bias, $\beta$, and standard deviation, $\sigma$ ) to gauge the agteement of the commonly used empirical upper atmospheric models (MSISE-90 and, Jacchia-70) and the new model, NRLMSISE-00, with the NRIMSIS database. Generally, the bias is the weighted mean of the residuals $\left\{d_{i}-m_{i}\right\}$ between the data set $\left\{d_{i}\right\}$ and the corresponding model estimates $\left\{m_{i}\right\}$, thereby measuring their systematic differences. The weighting factor for a given data point is the squared reciprocal of the attribured error, and angle brackets "( $)$ " denore the weighted mean. Positive bias $(\beta)$ indicates that a model underestimates the measured density values on average while negative bias signifies overestimation. The standard deviation is $\left(\left(\left(d_{i}-m_{i}\right)^{2}\right\rangle-\beta^{2}\right)^{1 / 2}$ and measures a model's coverage of the time scales and phases implicit in the data. However, $\sigma$ also reflects the noise implicit in the data sets, so that the standard deviation can be somewhat ambiguous. When the three models are compared with identical data sets, the relative values of $\sigma$ should give an indication of the agreement of the various models with measured time scales and the associated phases.

The NRIMSIS database consists of rwo components: the complete dara sets acquired from the various sources and the subset of data "selected" to generate the model. Hedin et al. [1977] described the selection process, which was designed to ensure the widest coverage of the hyperspace of subroutine arguments while satisfying constraints imposed by computing and 
storage limitations. Hedin's method also avoids dominance of the model coefficients by only a few large data sets, although this can also be accomplished by proper weighting of data-model residuals in computing $\chi^{2}$. In order to insure against domination of NRIMSISE-00 by the new data sets and to maintain consistency with past MSIS versions, we have perfonned a similar selection from the new data.

The tables of $(\beta, \sigma)$ values include both the model generation database and the complete, newly added data sets. For temperature $T$, the tables show $\beta \equiv\left\langle T_{i}\right.$ (data) $-T_{i}$ (model) $)$ and $\sigma \equiv$ $\left(\left\langle\left[T_{i}(\text { data })-T_{i}(\text { model })\right]^{2}\right\rangle-\beta^{2}\right)^{1 / 2}$. For species number density and total mass density, we have computed the bias as $\beta=\exp \left(\log _{e}\left(p_{i}(\right.\right.$ data $\left.) / p_{i}(\operatorname{model})\right)-1$ to provide an average fractional density bias and have computed the standard deviation as $\sigma=\left(\left\langle\log _{e}{ }^{2}\left\{p_{i}(\right.\right.\right.$ data $\left.\left.) / p_{i}(\operatorname{model})\right\}\right\rangle$ $\left.\beta^{2}\right)^{1 / 2}$. The number of tables is sufficiently large that they have been placed in the AGU Electronic Dataset Archive for access by interested readers. In our discussion below, we denote these tables by $A \mid(a)-(c)$ to $A 9(a)-(c)$, where " $A$ " signifies "archive" and $(a)-(c)$ denore, respectively, quiet $\left(A_{p} \leq 10\right)$ and active $\left(A_{p} \geq 50\right)$ geomagnetic conditions and the union of all geomagnetic conditions ("all" data). The tables abbreviate the names of the models to N00 (NRLMSISE-00), M90 (MSISE-90), and J70 (Jacchiz-70). The tables cove- total mass densiry (p), temperature, and individual species (excluding anomalous oxygen). For the tables relating to quiet conditions and to all data, the calculations used only data points deviating from the new model by $15 \times$ the associated error, or less. For active conditions, the database was sufficiently sparse that all high activity poinis were used to construct the tables. Finally, for "all" and $A_{p} \geq$ 50, we used the $3 \mathrm{hr} \mathrm{a}_{\mathrm{p}}$ inputs to the NRLMSISE-00 (NOO") and MSISE-00 ("M90") models, while for quiet conditions, we used the daily $A_{p}$ input.

The bias and standard deviation are coarse measures, and are useful primarily for simple error analysis. Statistical differences among models often appear to be moderate and are not consistent across all data sources, potentially masking trends and systematic differences. Relative to our database, the most obvious differences among the models involve the standard deviation of the nodel-data residuals. While $\sigma$ is comparable among the models regarding temperature and total mass density, NRIMSISE-00 show's better performance for composition, especially as altiwde increases. The latter effect also occurs for exospheric temperarure but is not pronounced. For Jacchia-70, the best temperature results relative to the MSIS-class madels occurred for the 
combination of lower altitudes and satellite-based observations. Ai high geomagnetic activity, comparisons with the data showed similar or degraded performance of all models relative to the low geomagnetic activity cases.

Consideration of key drivers or variations makes the differences among models more apparent (e.g., see the next section on variations with the solar EUV flux, as represented by $\left.F_{10.7}\right)$. In addition, comparisons of the models for selected data sets can sometimes be illuminating, if the user has knowledge of those particular data sets, if the data sets derive from the same or similar sources, or if particular altitude or geomagnetic activity ranges are emphasized. As an example and as an introduction to Section 4.1 on anomalous oxygen contributions to total mass density. Table I below compares the Jacchia data set to the three $\Rightarrow$ models. As indicated above, the table show that the biases and standard deviarions of the three models are comparable in magnitude; this especially true for $p$, across all sccelerometer and drag data sets. However, two additional, secondary features appear. First, the Jacchia model shows a consistent negative bias, on average overestimating the Jacchia data. Section 4.1 shows that this

1 to is likely attributable to a nonoptimal match with $F_{10.7}$ variability of the data. Second, at high geomagnetic activity, the standard deviations of the M90 and 370 models are consistently higher than that of NRLMSIS. This suggests that the new model handles spatial and seasonal variability somewhat better than the other models at elevated geomagnetic activity. In Deither case, however, does $\beta$ or $\sigma$ allow us to make a strong inference.

\section{Table 1}

STATISTICAL COMPARISON OF EMPIRICAL MODELS TO JACCHIA DATA

\begin{tabular}{|c|c|r|r|c|c|c|c|c|}
\hline \multirow{2}{*}{ Ap } & \multirow{2}{*}{ Altitude } & Points & \multicolumn{2}{|c|}{ N00 } & \multicolumn{2}{|c|}{ M90 } & \multicolumn{2}{|c|}{ I70 } \\
& & & $\beta$ & $\sigma$ & $\beta$ & $\sigma$ & $\beta$ & $\sigma$ \\
\hline$\leq 10$ & $200-400$ & 6236 & -0.06 & 0.17 & -0.06 & 0.17 & -0.04 & 0.17 \\
\hline & $400-800$ & 10041 & -0.07 & 0.23 & -0.08 & 0.26 & -0.07 & 0.25 \\
\hline & $800-1200$ & 5586 & 0.01 & 0.23 & 0.03 & 0.27 & -0.05 & 0.23 \\
\hline & $>1200$ & 15 & 0.20 & 0.09 & 0.27 & 0.10 & -0.18 & 0.05 \\
\hline All & $200-400$ & 10456 & -0.07 & 0.17 & -0.06 & 0.17 & -0.07 & 0.19 \\
\hline & $400-800$ & 16021 & -0.08 & 0.25 & -0.07 & 0.27 & -0.09 & 0.28 \\
\hline & $800-1200$ & 9373 & 0.01 & 0.24 & 0.04 & 0.27 & -0.07 & 0.25 \\
\hline
\end{tabular}




\begin{tabular}{|r|r|r|r|r|r|r|r|r|}
\hline & $>1200$ & 24 & 0.22 & 0.12 & 0.30 & 0.11 & -0.20 & 0.13 \\
\hline$\geq 50$ & $200-400$ & 304 & -0.05 & 0.23 & -0.07 & 0.23 & -0.12 & 0.25 \\
\hline & $400-800$ & 441 & -0.01 & 0.36 & 0.01 & 0.39 & -0.17 & 0.42 \\
\hline & $800-1200$ & 282 & 0.07 & 0.35 & 0.05 & 0.39 & -0.14 & 0.39 \\
\hline
\end{tabular}

\section{Scientific and technical issues}

\subsection{Anomalous oxygen and solar activity}

\subsubsection{Background}

7 As shown by Hedin [1989], both the Jacchia model and data from the neutral mass spectrometer aboard Dynamics Explorer-2 (DE-2) indicated that an appreciable hot atornic oxygen population could be present at high latitudes and altitudes $(>600 \mathrm{~km})$ during the summer. The DE-2 measurements showed an elevated oxygen component under moderate to high solar activity, consistent with suggestions by Yee er al [1980]. that a hot oxygen geocorona might exist with temperature of $-4000 \mathrm{~K}$. For low solar activity, at high altitudes and summer high latitudes, the Jacchia-70 model showed significantly higher total mass density (and helium concentration) than did MSIS-86. Hecin hypothesized that a hor oxygen geocorona could cause these discrepancies.

Recent analyses of ISR data by Oliver [1997] and Oliver and Schoendorf [1999] have argued for a small, but non-negligible, hot oxygen component (emphasizing altitudes around 400 $\mathrm{km}$ ), especially at night and at the solscices during solar minimum. Schoendorf et al. [2000] have developed model profiles of hot oxygen for use in aralyzing incoherent scatter radar data, e.g., to derive $T_{e x}$ (Section 4.3). While the ISR sites are somewhat lower in latitude than our region of interest (see below), a broadening of the investigations by Oliver et al. should significantly augment the present understanding of the hot oxygen component and could guide our furure upgrades of NRLMSIS.

The emphasis on hot atomic oxygen changed significantly when Keating et a]. [1998] analyzed neutral and ion mass spectrometer measurements aboard the Midcourse Space Experiment (MSX), which flew in a sun-synchronous (near-polar) circular orbit at approximately $900 \mathrm{~km}$ during the most recent solar minimum. Based on comparisons of the Jacchia-70 and 
MSIS-86 models, similar to those of Hedin, Keating et al, showed that the measured $O^{+}$ concentration could account for the discrepancy in the respective model estimates of [He] and total mass density.

In response to these developments, the NRIMSIS model now includes an "anomalous oxygen" (AO) component, which represents any appreciable, persistent $\mathrm{O}^{+}$and hot $\mathrm{O}$ populations at bigher altitudes $(>500 \mathrm{~km}$ ). The functional form of the anomalous oxygen model profile is similar to that of an isothermal Chapman layer, with an adjustable magnitude and scale height (or temperature; Appendix A.1). The data used to evaluate these parameters were simply the Jacchia and Barlier (JB) data above $600 \mathrm{~km}$. At the same time, we excluded the summer JB data above $600 \mathrm{~km}$ from the data sets used to deternine the He and "cold" O components of the model. While the winter data above $600 \mathrm{~km}$ are common $10 \mathrm{He}$, cold $\mathrm{O}$, and anomalous $\mathrm{O}$, our tests have shown small differences between NRLMSISE-00 and MSISE-90 for these data, indicating less influence of the additional oxygen component on the new model during winter at high altitudes. Surprisingly, the Jacchia -70 model appears to agree less well with the Jacchia data under such conditions (next subsection).

Our anomalous oxygen data se: does not include the high altitude, spin-mode DE-2 neutral mass spectrometer data [Hedin, 1989] for several reasons:

(1) The drag data should account for both $\mathrm{O}^{+}$jons and hot $\mathrm{O}$ atoms while the DE-2 data account only for the neutral atoms. Therefore, the DE-2 data could bias the fit against the $\mathrm{O}^{+}$ component detected by the MSK analysis.

(2) Retrieving the hot oxygen component of DE-2 data is dependent on using a model for the cold oxygen component.

(3) The DE-2 data have further limitations: small number of points (425) above $600 \mathrm{~km}$, high solar activity (average $\mathrm{F}_{10.7}$ above 190), and narrow temporal coverage (only fall-winter of 1981-2).

Fortunately, a comparison of the Jacchia-Barlier data to the DE-2 data for high latitudes and elevated solar activity (81-day average: $\left.\left\langle F_{10.7}\right\rangle>150\right)$, shows good qualitative agreement, implying that the drag-based data set has captured the elevated neutral density implied by DE-2. A tantalizing result is that the fir of the NRLMSIS aromalous oxygen component to the high- 
altitude Sacchia-Barlier total mass density data yielded an effective temperature of approximately $4177 \mathrm{~K} \pm 3 \%$. We do not hold this to be definitive, given the limitations of our high altitude drag Jata set, and we have therefore chosen to maintain this parameter at $4000 \mathrm{~K}$, in line with previously cited references on hot oxygen. Note that such a temperature would seern to be too high for oxygen ions to form the primary component of our anomalous oxygen model. Clearly we need more data on, and modeling of, neutral and ionized atomic oxygen at high altitudes to develop a faithrul representation of the atmosphere near the exobase.

\subsubsection{Comparison of models with high altitude Jacchia data}

Comparison of madels with the Jacchia data above $600 \mathrm{~km}$ reveal both anticipated and unexpected features. First, the high altitude Jacchia data support the observations of Keating et al. [1998], regarding a significant enhancement in total mass density over past MSIS-class models, for the combination of low solar activity, high altitude, and high summer latitudes. However, this difference decreases rapidly with increasing $F_{10.7}$ and decreasing altitude, and surprisingly, the Jacchia-70 model significantly overestimates the observed density at very low F10.7. Further, as a function of $F_{10.7}$ under the corresponding winter conditions, MSIS-class models generally agree better with the Jacchia data than does the Jacchia-70 model itself. As a result, NRLMSISE-00 achieves improvements over both MSISE-90 and Jacchia-70, incorporating advantages of each.

Figures 1 and 2 compare the (previous day) $F_{10.7}$ - dependence of the total mass density from four sources: (1) the Jacchia data set on total mass density (data denoted here by $p_{\mathrm{J}}$ ), (2) the corresponding NRLMSISE-00 model values $\left(p_{N}\right)$, (3) the MSISE-90 model values ( $P_{M}$ ), and (4) the Jacchia-70 model values $(p$ ). The Jacchia-70 model values provide a baseline, since the Jacchia models are the scandard of the astrodynamics community for estimating orbital drag. The Iigures depict bin-averaged differences of natural logarithms, $\log _{e}\left(\rho_{N} / \rho_{1}\right)$ denoted by solid lines, $\log =\left(\rho_{M} / \rho_{j}\right)$ denoted by dashed lines, and $\log _{e}\left(\rho_{d} / \rho_{j}\right)$, located at the centers of the $\pm 1 \sigma$ vertical bars ( $\sigma=$ standard deviation). The averaging bins are $10 \mathrm{~F}_{10.7}$ units, and both abscissas and ordinates are averages over individual bins. The number at the center of a vertical bar is the approximate base 2 logarithm of the number of points in the corresponding bin. The solid horizontal line at an ordinate of 0.0 represents the bin-averaged Jacchia-70 values. When a verical bar is approximately centered on the horizontal line, the Jacchia-70 model is in good 
agreement with the daca in the given bin. Significant displacement of a vertical bar from the horizontal line signifies poor performance by Jacchia-70.

Figure 1(a) shows the solar activity dependence of $\rho$ above $900 \mathrm{~km}$ for the combination of summer and high latitudes $\left(|\theta| \geq 45^{\circ}\right)$; the MSX data of Kealing et al. [1998] correspond to (previous-day) $F_{10.7}=71$, altitude $z=900 \mathrm{~km}$ and $\theta=80.6^{\circ}(\mathrm{N})$. For low to moderate solar activity (75-175), the Jacchia-70 model captures the trend and magnitude of the data somewhat better than does NRIMSISE-00. A comparison to MSISE-90 verifies the enhancement observed by Keating, but this effect diminishes as $F_{10.7}$ approaches 130 . Unexpectedly, as $F_{10.7}$ decreases below 75 , the Jacchia-70 model overestimates the total measured mass density by an increasing amount. In fact, below $F_{10.7}-75$, NRLMSISE-00 appears to agree with the Jacchia data better than does Jacchia-70, while above - 130 the differences between the two models are relatively small. For the entire data subser containing 684 points, we may also compare the usual statistical measures, i.e., standard deviation, $\sigma$, and bias $\beta \equiv\left\langle\log _{s}\left(\rho_{d} / \rho_{\text {model }}\right)\right\rangle$, where "model" signifies NRIMSISE-00, MSISE-90, or Jacchia-70, where brackets indicate an average over the data subset, and where the contribution of each darum to both averages has been weighted by the squared reciprocal of the attributed error. The values of $(\beta, \sigma)$ are $(-0.08,0.22)$ for NRLMSISE00 and $(-0.10,0.24)$ for Jacchia-70, implying no particular advantage to either model, in spite of the differences in Figure 1(a). MSISE-90 has $(\beta, \sigma)=(0.19,0.29)$, indicating a systematically Iow average density estimate and a poorer match of the observed $F_{10.7}$ dependence.

Figure 1(0) shows the situation for Jacchia's data set during summer at high latiudes in the altitude range $600-900 \mathrm{~km}$ (1085 points). Comparisons with MSISE-90 show that the effect observed by Keating et al. has decreased considerably in both peak value and the operative range of F10.7. Moreover, NRIMSISE-00 appears to give better agreement with the dependence of the data on $F_{10.7}$ than does Jacchia-70, and agrees especially well with the data at low solar activity. The statistical measures are $(\beta, \sigma)=(-0.08,0.25)$ for NRLMSIS versus the Jacchia-70 values of $(-0.02,0.31)$. MSISE-90 has values of $(0.05,0.34)$, primarily due to poorer agreement at low solar activity. Notice that the bias ( $\beta$ ) values of the models are insensitive to the striking differences in variation with $F_{10.7}$ and actually attribute a modest advantage to Jacchia-70, while $\sigma$ gives a coarse indication that NRIMSISE-00 does a better job matching the F10.7 dependence. 
In winter, for the same combination of latitude and altitude, the MSIS-class models generally outperform Jacchia-70 when compared to the Jacchia dara set as a function of $F_{10.7}$. Figure 2(a), for $z \geq 900 \mathrm{~km}$, shows that the Jacchia model gives somewhat better agreement at low $F_{10.7}$ but varies oppositely with the data as $F_{10.7}$ increases. At $F_{10.7}=98$, the NRIMSIS and MSISE-90 models do show a $45 \%$ overestimate, but this is based on only two data points. In fact for $F_{10.7}$ in the range $80-120$, only 19 data points were available, making the low $F_{10.7}$ range difficult to evaluate. Actoss the entire range of solar activity, the differences among models show up in the model biases: $(\beta, \sigma)=(-0.06,0.19)$ for NRIMSISE-00 and $(-0.12,0.20)$ for MSISE-90 versus the Jicchia- 70 values of $(-0.24,0.15)$.

Figure 2(b), for $z=600-900 \mathrm{~km}$, shows similar but less extreme differences in bias, with $(\beta, \sigma)=(-0.14,0.19)$ for NRLMSISE-00, $(-0.22,0.21)$ for MSISE-90 and $(-0.20,0.20)$ for Jacchia-70. The biases are closer primarily because the number of data points decreased with increasing $F_{10.7}$, for which the deviation of Jacchia-70 from the Jacchia data was also increasing.

The respective $\beta$ and $\sigma$ values for NRLMSISE-00 and Jacchia-70 are remarkably similar, especially for the cases in Figure 1, demonstrating that statistical averaging can mask qualitative differences. Such filtering of model estimates by averaging over one or more arguments might explain the comparable performance of MSISE-90 and Jacchia-70 for "special perturbations (SP)" orbit deternination [Marcos et al., 1998]. The SP calculation fits a derailed numerical propagatos (including drag) to space object observations covering a fit span of several days and acts to filter the density model over the fit span [Neal et al., 1998]. In addition, one of the fitting parameters is the "ballistic coefficient," which multiplies the atmospheric density in the drag term; adjusting the ballistic coefficient corrects the model bias over the fit span [Marcos et al., 1998]. On the other hand, the detailed differences among models play a large role in the important function of orbit prediction, for which no observations of the space object are available.

4.2. Solar ultraviolet occultation vs. mass spectrometry

As indicated above, we have inclyded the UV occultation observations of [ $\left.\mathrm{O}_{2}\right]$ by the Solar Maximum Mission (SMM: [Aikin et al., 1993]) in generating the new model. We have also included UV occultation data derived from a second band (channel 19) on the AE-E EUVS instrument. Prior to NRLMSISE-00, mass specrometer data were more numerous than were 


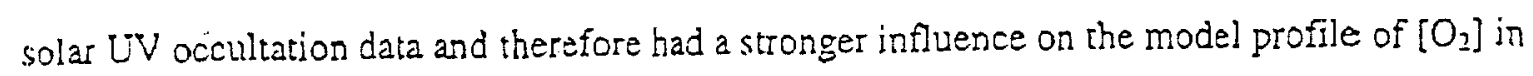
the lower thermosphere. Furthermore, the UV occultation data were available only at very low altitudes $(\leq 150 \mathrm{~km})$, where comparisons batween the two data sources were less definitive [Aikin et al., 1993]. As a consequence, the MSISE-90 profile of $\left[\mathrm{O}_{2}\right]$ is in spproximate diffusive equilibrium above - $150 \mathrm{~km}$ [Mejer et al, 2001], whereas observations by solar UV occultation differ from diffusive equilibrium by an increasing amount as altitude increases within the range $140-240 \mathrm{~km}$ - a longstanding controversy [Aikin et al. 1993, and refe-ences therein]. Genera] circulation models and other detailed chemistry/dynamics models also depart from diffusive equilibrium in the lower and middle thermasphere [Meier et al., 2001].

The SMM UV daca also show weaker solar activity dependence than do the mass. spectrometer data [Aikin et al., 1993]. As a result of these differences, we have modified the paraneterization of the lower themospheric altitude profiles of $\mathrm{O}_{2}$ and $\mathrm{O}$ to allow more flexibility in NRLMSISE-00, as described in the Appendix. The model can now accommodale solar activity dependent departures from diffusive equilibrium in the lower themosphere. Figure 3(a) shows that the new model compromises between the two data cources in the altitude region $125.225 \mathrm{~km}$ covered by the SMM dara. Above this region the NRLMSIS $\left[\mathrm{O}_{2}\right]$ proflle approaches diffusive equilibrium, and below this rejion, the rwo data sources agree is the atmosphere appioaches a fully mixed state.

Figure 3(b) shows the dichotomy berween the newly added data and the previously existing data, from which the MSISE-90 model (horizonial line at 0.0 ) was generated. The low altitude AE-E UV occultation data (labeled $D$ and $E$ ) extended the solar acrivity dependence of the MSISE-90 database. These data are reasonably consistent with MSYSE-90, with mass spectrometer data, and with low altitude, low $F_{10.7}$ A.E-C UV occultacion data (Figure $3(a)$ and [Aikin et al., 1993]). On the other hand, the newly added SMM data and the rocker and AE-E UV occultation data at $150 \mathrm{~km}$ (labelled $\mathrm{K}, \mathrm{M}$, and $F$ and $W$, respectively) are not generally consistent with the MSISE-90 model, although these data appear to be consistent with each other. Figures $3(a)$ and $(b)$ show that the magnitude of the disagteement depends on both altitude and $F_{10.7}$, as indicated above.

Figure $3(b)$ also verifies that the SMM data on $\left[\mathrm{O}_{2}\right]$ depend more weakly on $\mathrm{F}_{10.7}$ than does MSISE-90, which did not include those data. Figure $3(c)$ demonstrates that the new 
NRLMSISE-00 model fits the $\left[\mathrm{O}_{2}\right]$ catabase far better than MSISE-90, primarily because of the adjustment to the profile in the region of transition from a fully mixed state to diffusive equilibriurn.

This leaves open the question of accuracy for both mass spectrometry and solar UV occultation. Before the NRLMSIS models can properly portray the altitude dependence of $\left[\mathrm{O}_{2}\right]$, the community must resolve this fundamental conflict of the two major data classes. Note in the Appendix that the $[\mathrm{O}]$ profile in the lower thermosphere has also changed to accommodate both the SMM data and the mass spectrometer data on total oxygen number density, $[\mathrm{O}]+2\left[\mathrm{O}_{2}\right]$. The latter data are our primary source of information to set the [O] model in NRLMSISE-00. Comparison of the new model with our total oxygen data shows an improvement in standard deviation, but the new model is quite similar to MSISE-90 regarding total oxygen content.

\subsection{Exospheric temperature}

The Millstone Hill and Arecibo incoherent scatter radar data on exospheric ternperature $\rightarrow\left(\mathrm{T}_{\text {ex }}\right)$ are high quality and extend the NRLMSIS database well into the 1990s. These data derive from ñtting a model of ion heat balance and chemistry to the ion temperature profile $\left(T_{i}(z)\right)$, using ISR observables and parameterized models of neutral oxygen and temperarure [e.g., Buonsanto and Pohlman, 1998]. The retrieval of $T_{e x}$ from the ISR data did not include a hor oxygen component [Schoendoff et al. 2000]. The newly added Millstone Hill data, shown in Figure 4(a), cover the period 1981-97. The data include the June, 1991, geomagnetic storm with maximum $\left\{F_{10,7}, a_{p}\right\}-\{250,300\}$ (see Livin et al. [2000] and references therein) and another period around October 29,1991 with maximum $\left\{F_{10.7}, a_{p}\right\}-\{270,235\}$. Litvin el al. pointed out that during the most intense stom period of June, 1991, molecular ions dominated the chemistry, requiring a modification in the algorithms used to retrieve $T_{\text {ex }} ;$ a similar situation apparencly occurred in late October. Even after this correction, however, $T_{e x}$ ranged significantly below the predictions of MSISE-90 for both periods. In fact, given that the difference was greater in October, 1991, when $F_{10.7}$ was higher (Figure $4(a)$, abscissa -275 ), the elevated $F_{10.7}$ might also be a factor in the lower value of $T_{\text {ex }}$.

Figure $4(b)$ shows the variation of the new Arecibo ISR data with previous day $F_{10.7}$; these data also include periods of high geomagnetic activity, with some daily $A_{p}$ values well over 50. Interestingly, MSISE-90 provides a somewhat better fit at high solar activity $(\geq 240)$ than 
does NRLMSISE-00, suggesting that the response to solar forcing might vary with lacitude. Uniortunately relatively few data points are available at such high values of $F_{10.7}$ and the database has not supported retrieval of a meaningful latitude-F10.7 coupling term. Indeed, no clear advantage for either model emerges from comparison with the entire Arecibo data set on upper themospheric temperature, which covers the last thirty-five years.

The findings by Millstone Hill under elevated geomagnetic activity in 1991 led naturally to a search for Arecibo measurements that intersected with Millstone Hill data during 1991. Two such periods occurred early in the year (mid-January and mid-March). At those times $F_{10.7}$ was high (180-275) while $A_{p}$ was low to moderate (<35). During these periods, the temperature bias relative to NRLMSISE-00 bad the same sign at both ISR sites - negative for mid-January with $\left(F_{107}-180-220\right)$ and positive for mid-March when $\left(F_{10.7}-240-275\right)$. The respective biases were also similar in magnitude, though $20-40 \%$ less than the biases during the June and Ociober storm periods. The similarity of biases at the two sites during lower geomagnetic activity points to a global erro: source in the model; an example is the use of $F_{10.7}$ as a proxy for the solar EUV flux, which drives variability of the themospheric densiry on time scales of a day or longer. Bass er al. [1996] and Rhoden er a]. [2000], respectively, have used drag and accelerometer daca to explore other proxies as candidares to augment or replace $F_{10,7}$. On the other hand, the differing signs of the bias during these lower geomagnetic activity periods contrasts with the decidedly negative bias observed during mid- and late 1991, when maximum a was very high.

Most importantly, the new ISR and total mass density data, when combined with the previous MSIS data sets, have changed the solar activity dependence of the temperature in NRLMSISE-00, relative to that of MSISE-90 (and MSIS-86), especially at higher altitudes. Figure 5 shows the difference in mean exospheric temperature estimates produced by the models as a runction of latitude and $\left\langle F_{10.7}\right\rangle$. The NRLMSISE-00 $T_{\text {ex }}$ is above that of MSISE-90 only at low latitudes and for moderate to low $\left(F_{10.7}\right)$ and then by only a few degrees. As solar activity increases above moderate values, the NRIMSISE-00 value of $T_{\text {ex }}$ falls below that of MSISE-90 by a steadily increasing amount, reaching $-40 \mathrm{~K}$ at $\left(F_{10.7}\right)>220$ and high latitudes, $|\theta|>45^{\circ}$. This difference is less pronounced at lower latiudes, as we might expect from Figure 4(b). The mean total mass density behaves similarly to the temperature. Checks of the individual NRLMSISE-00 data sets an composition, temperature, and density have generally confirmed this behavior. 


\subsection{Mesosphere inversion layers}

Mesosphere inversion layers $(\mathrm{MI})$ are regions of enhanced temperature $(\Delta \mathrm{T}-15-50 \mathrm{~K})$ which have been observed in the upper mesosphere and at the mesopuuse at low and midlatitudes and primarily at night [Meriwether and Gardner, 2000]. Present theory attribures the phenomenon to enhancement of tidal structure through interaction with gravity waves; ultimately, a more comprehensive database of 24-hour observations in the mesosphere and lower thermosphere will be needed ro confirm and complete the theory. Quantitative analysis of the MII phenomenon is well beyond the scope of the present paper and the empirical model; here we merely point out NRLMSISE-00 does exhibit the shape of an upper ML near the mesopause ar low latitudes during the nighttime. Under these conditions, this feature is more prominent in the new model than in MSISE-90 and warants mention. Figure 6(a) shows a comparison of MSISE-90 and NRLMSISE-00 under these conditions while $6(b)$ shows a similar dayside comparison. The structure becomes less apparent at mid-latitudes, covers a broader altitude range, and appear to be less prominent at midnight than do the annual mean upper MIL profiles shown by Meriwether and Gardner. In this region, the NRLMSIS database contains only a few rocket observations ( -60 temperature values), which do not appegr to have sufficient information to cause this behavior in the model. The figure shows primarily that the formulation is sufficiently flexible to capture $\mathrm{MIL}$ structures in data sets. Outside of the addition of new Millstone Hill LTCS data in the $100-130 \mathrm{~km}$ altitude range, the only major difference from the MSISE-90 model is the imposition of hydrostatic equilibrium over a wider range $(80-300 \mathrm{~km})$. The latter factor plus the lower oider tides in the model apparently have acted in concert to produce the MI-like structure. Generating realistic MIL profiles with NRLMSIS awaits upgrading the model with the recent, extensive database of ground-and space-based observations of the upper mesosphere and mesopause.

\section{NRLMSIS Model - Present and Future}

The new database underlying the NRLMSISE-00 model incorporates data on total mass density (orbitsl drag and satellite accelerometers), recent incoherent scatter radar observations covering more than a solar cycle, and satellite-borne FUV occultation measurements of $\left[\mathrm{O}_{2}\right]$ from SMM. The model interpolates among newly added and past data sets, often incorporating strengths or features of each data set. As a result, the exospheric temperature in NRLMSISE-00 
now shows somewhat weaker dependence on $F_{10.7}$ relative to MSISE-90. In the lower themosphere, the model compromises between mass spectrometer and ultraviolet occultation data in terms of the altirude dependence of $\left[\mathrm{O}_{2}\right]$ but follows the weaker solar activity dependence of UV occultation data mote closely.

The incorporation of satellite-based data on total mass density has allowed the inclusion of a new component - "anomalous oxygen" - to correct the model estimates of total density at high altitudes (near the exobase). This recognizes the conclusion of Keating et a. [1998] that $\mathrm{O}^{+}$ can dominate drag under particular conditions and, through similar analysis, the conclusion of Hedin [1989] that hot oxygen could be importast to drag. Comparison of NRLMSIS and the siandard operational and scientific models to the orbit-based data of Jacchia at high alticudes has revealed significant differences in the seasonal and solar activity dependence of the models. The new model appears to provide advantages over both Jacchia-70 and MSISE-90 for estimating lotal mass density.

The broadening of the database, along with comments by users and plans to replace or augment the $F_{10.7}$ input with a superior index of the solar chromospheric extreme ultraviolet (EUV) flux, have led to modifications in the model formulation:

1) A new coupling term between $F_{10.7}$ and mean $F_{10.7}$ (Appendix A.1) to pemit more flexibilicy in representing the dependence on solar EUV.

2) Anomalous oxygen model in upper themosphere to allow for increased drag under some condicions;

3) Upgraded representation of $\left[\mathrm{O}_{2}\right](z)$ in the lower thermosphere to allow more general and higher alcitude departures from diffusive non-equilibrium and weaker solar activity dependence [Aikin et al., 1993];

4) New $[0](z)$ parameterization in the lower thermosphere to compensate for changes in the new definition of $\left[\mathrm{O}_{2}\right](z)$, primarily when fitting mass spectrometer data on total oxygen content, $[\mathrm{O}]+2\left[\mathrm{O}_{2}\right]$;

5) Hydrostatic equilibrium constraint over a wider altitude range to the the upper and lower armospheric regions together self-consistently;

6) Nonzero thermal diffusion factor for Ar. 
Item (5) is particularly interesting, in that NRLMSISE-00 produces a remperature structure similar to a mesosphere inversion layer under some conditions (e.g., equatorial region at night, low lacitudes), even though our most proximate new temperature data are above the mesopause (altitude range 100-130 km (Goncharenko and Salah, 1998]). We attribute this effect to the self-consistent imposition of hydrostatic equilibrium across the mesopause, in combination with the interaction among low order tides. Presumably the next generation NRLMSIS model will provide a more accurale climatology of the MIL when the relevant satellite- and groundbased data are added to the database.

An underlying theme of this paper and of our furure work is the dependence of the upper atmosphere on the solar EUV tlux, which is the primary driver on time scales of a day or longer. Section 4 shows that the dependence on the $F_{10.7}$ solar EUV proxy is different for the respective empirical models favored by operational and seientific communities. The new NRLMSISE-00 model appears to incorporate advantages of both model classes and therefore helps to clase the gap between these models. In addition, the atmospheric calibration method of Marcos et al. [1998] and a follow-on implementation in terms of ultraviolet remote sensing use near-real-time atmospheric data to improve density escimation for the "present" epoch [Nicholas et al., 2000]. Ultinately, however, the operational community seeks a better predictive capability. Marcos et al. [1998] have shown that the most likely route to this goal is through better solar EUV inputs to the models, such as that by Lean et al. [2001]. Under funding by the NASA Living With a Star Program, we are now pursuing this approach.

\section{Acknowledgements}

The authors gratefully acknowledge primary support by the Office of Naval Research, early support for one of us (A. Hedin) by the NASA Supporting Research \& Technology Program, and recent support by the NASA Living With a Star Program. GenerousIy providing new data sets and vital assistance to us were the following: Frank Marcos (AFRL: accelerometer data); Francois Barlier (drag data, including those of Jacchia); Steven Cariglia, John Holt, Joseph Salah, and Michacl Buonsanto (Millstone Hill, MIT Haystack Observatory: $T_{\text {ex }}$ ); Joseph Salah and Larisa Goncharenko (Millsione Hill, MTT Haystack Observatory: Lower Thermosphere Coupling Study, $T_{100-130}$ ); and Michael Sulzer and the CEDAR Database (Arecibo: $T_{x x}$ ). Millstone Hill, through its staff members John Holt, Michael Buonsanto, and Steven Cariglia, 
kindly invited and trained our research associate Owen Kelley, who retrieved $T_{\text {ex }}$ from both the Millstone Hill and the Arecibo data sets in the Madrigal Dutabase. The data provided by the Millsione Hill incoherent scatter radar were obtained under a National Science Foundation cooperative agreement with MTT, ATM-9714593. Robert Meier performed extensive testing of the new model in spectral inversion and data-fitting codes, and John Mariska and John Holt tested the distribution package on a number of operating systems. We have also received invaluable guidance from William Oliver, Dariel Melendez-Alvira, Raymond Roble, and Anatoli Pavlov.

Appendix: NRLMSISE-00 formulation, constraints, generation, and distribution package A.1. Formulation

The Appendix of Hedin [1987] defines the thermospheric portion of the MSIS-class models, for which the fundamental variable is the temperature $T(z)$. The Bates-Walker temperature profile variables [Walker, 1965] are the exospheric temperature, $T_{c x}$; the temperature at $120 \mathrm{~km}, \mathrm{~T}_{120}$ and the temperature gradient at $\mathrm{z}_{\mathrm{ib}} \equiv 120 \mathrm{~km}$. These variables have the form (e.g., for $\left.T_{12 n}\right)$

$$
T_{120}=\bar{T}_{120}\left[1+G_{120}(L)\right] \text {, }
$$

where the overbar signifies a global and cemporal mean and the function $G(L)$ includes constant, spherical harmonic, and harmonic terms, some of which are coupled and whose coefficients and phases represent the spatial and temporal time scales inherenc in the data. In addition, $G(L)$ contains polynomial or exponential terms in the solar EUV proxy $\left(F_{10.7}\right.$ and $\left\langle F_{10.7}\right\rangle$, the 81-day average) and in geomagnetic activity. For chemical species $i$, the Bates-Walker profile variable is the number density at $120 \mathrm{~km}$

$$
n_{i}=\bar{n}_{i} \exp \left[G_{i}(L)\right] .
$$

The subscript on $G$ distinguishes among unique coefficient sets for respective thermospheric variables in the model. The Bates-Walker profile represents species in themal and diffusive equilibrium and includes thermal diffusion. Below a species-dependent altitude in the range 160 $450 \mathrm{~km}$, the model profiles differ from diffusive equilibrium by progressively greater amounts as $z$ decreases, transitioning to a fully-mixed state at a turbopause $z_{h}-100 \mathrm{~km}$. In that region, 
MSIS-class models modify the density profile due to the effects of chemistry, dynamics, and loss and flow processes.

The NRIMSISE-00 model incorporates the following modifications of the equations in Hedin [1987]:

(1) The solar EUV dependence includes a new cross term with coefficient $B \neq 0$ :

$$
G(\text { Solar })=A \Delta F(1+B \Delta(F))+C(\Delta F)^{2}+D \Delta\langle F\rangle+E(\Delta\langle F\rangle)^{2} \text {, }
$$

where $\left\langle F_{10.7}\right\rangle$ is the 81 -day, time-centered average of $F_{10.7}, \Delta(F)=\left\langle F_{10.7}\right\rangle-150$, and $\Delta F=F_{10.7}$ $\left\langle F_{10.7}\right\rangle$.

(2) The "anomalous" oxygen model profile, $\left[\mathrm{O}_{2}\right](z)$, represents nonthemal oxygen species (e.g., $\mathrm{O}^{+}$and hot oxygen) inherent in the Jacchia and Barlier daia sets at higher altitudes $(\geq 600$ $\mathrm{kn}$ ) and is similar to an ionospheric Chapman layer (e.g., Cotton et al., [1994]),

$\left[O_{a}\right](z)=\left[O_{a}\right]\left(z_{1 b}\right) \exp \left\{-\frac{\xi\left(z, z_{l b}\right)}{H\left(z_{l b}, T_{a}\right)}\right\} \exp \left\{\frac{C}{H\left(z_{a}, T_{a}\right)}\left[1-\exp \left(-\frac{z-z_{a}}{C}\right)\right]\right\}$,

where the geopotential height is $\zeta\left(z, z_{l b}\right)=z-z_{l b}$, the scale height is $H(z, T) \equiv \frac{k T}{m g(z)}$, $m$ is the mass of atomic oxygen, and the constants are $C=76 \mathrm{~km}, z_{2}=550 \mathrm{~km}, T_{3}=4000 \mathrm{~K}, z_{15}=120 \mathrm{~km}$, and $\left[\mathrm{O}_{\mathrm{a}}\right]\left(\mathrm{z}_{\mathrm{b}}\right)$ (set by data $)=6.0 \times 10^{4} \mathrm{~cm}^{-3}$.

(3) Equations (A2Oa) and (A2Ob) of Hedin [1987] define a lower themospheric density muliplier $C_{1}$ in Equation (A12a); the purpose of this factor is to simulate chemistry and dymamic flow effects on various species. For $[\mathrm{O}]$ and $\left[\mathrm{O}_{2}\right]$ this factor now takes the form

$$
C_{1}=\exp \left\{\frac{R}{1+\exp \left[\left(z-z_{c}\right) / H_{c}\right]}\right\}
$$

where $R=R_{i}\left(1+a_{i} \Delta\langle F\rangle\right)$ and $i=0, O_{2}$. The constants are $R_{0}=-0.045, R_{O_{2}}=-0.78$, $\mathrm{a}_{i}=0.029, \mathrm{H}_{c}(\mathrm{O})=-\mathrm{H}_{\mathrm{c}}\left(\mathrm{O}_{2}\right)=21.2 \mathrm{~km}$ (Note: opposite signs), and $\mathrm{z}_{\varepsilon}(\mathrm{O})=\mathrm{z}_{\mathrm{s}}\left(\mathrm{O}_{2}\right)=129.4 \mathrm{~km}$.

(4) Consistent with Banks and Kockarts [1973], the thermal diffusion factors in NRLMSISE-00 are $\alpha_{i}=-0.38(\mathrm{i}=\mathrm{He}, \mathrm{EI}), 0.17$ ( $\left.\mathrm{i}=\mathrm{Ar}\right), 0.0$ (other species). This represents a change from MSISE-90, which had $\alpha_{i}=-0.4(\mathrm{i}=\mathrm{He}, \mathrm{H})$ and 0.0 (other species). PavJov [1979] and (private 
communication, 1998) suggests the following values: $-0.38(\mathrm{H}),-0.28\left(\mathrm{H}_{2}\right),-0.27(\mathrm{He}), 0.17$ (AI), $0.12\left(\mathrm{O}_{2}\right),-0.08(\mathrm{O})$, and $0.1\left(\mathrm{~N}_{2}\right)$.

\section{A.2. Constraints}

For altitudes $0 \leq z<z_{1 b} \sim 120 \mathrm{~km}$, the fundamental variables define nodes and gradients of the temperature profile, while pressure and density are defined by hydrostatic equilibrium and the ideal gas law [Hedin, 1991]. As mentioned above, diffusive equilibrium no longer holds for the MSIS-class models below altitudes - $300 \mathrm{~km}$. Because we fit the temperature and individual species separately (different coefficient sets), the MSIS-class models do not maintain hydrostatic equilibrium a priori. For this reason, the model generation process imposes an approximate hydroscatic equilibrium constraint in the region $80-300 \mathrm{~km}$. This couples the lower and upper atmospheric regions, modifying some derails of prevjous MSIS versions. Finally, since the new data all relate to the thermosphere, NRIMSISE-00 retained the MSISE-90 coefficients below while constraining coefficient values in the range $72.5-110 \mathrm{~km}$ to give a total mass density at the ground in agreement with MSISE-90.

\section{A.3. Model generation}<smiles>C1CC[Te]CC1</smiles>
Generating a new version of the model requires calculation of optimal values for the - 2200 nonzero coefficients. Even though only a subset of the MSIS database is used to evaluate [Hedin et al., 1977], the number of data points is still quite sizable $\left(-3 \times 10^{5}\right)$, rendering an inclusive Levenberg-Marquardi calculation [Press et al., 1992] compute-intensive and cumbersome. Because the NRIMSIS thermospheric data are separable by mass number (specjes, temperature, total mass density), one can partition the process into a series of separate Levenberg-Marquardt (LM) $\chi^{2}$ minimizacion calculations for coefficient and data subsets for different altitude regions, magnetic activity level, and scales of variability. Each complete series of LM coefficient calculations (presently numbering fifty-two) constitutes one "grand" fitting cycle. The grand cycles repeat until the coefficient set is stable [Hedin, 1987]. This approach has minimized memory requirements and maximized computing speed. We climinate severe oulliers by selecting only data points whose residuals are less than a specified multiple $(6-15)$ of the observational uncertainty. 
The new drag and accelezometer data represent a significant deparure from the above picture. In the present case, the total mass density provided by the model is a secondary or inferred quantity, given by the sum of species mass densities, apparently requiring that all of the species coefficients vary simultaneously to fit the data, which are extensive. To avoid this and other procedural difificulties, one can lake advantage of the fact that different theimospheric species doninate the mass density in different altitude regions. Specifically, for $\mathrm{N}_{2}, \mathrm{O}_{2}$, and He, we have used the MSISE-90 model to determine the altirude ranges where the respective mass fractions are greater than $50 \%$, thereby splitting the data into subsets. We have added these data subse is to the databases supporting the individual species coefficients and have combined the calculations of coefficients for $N_{2}$ and exospheric temperarure $\left(T_{e x}\right)$. As described in Section 4.1. we have extracted the high altitude $(\geq 600 \mathrm{~km})$ Jacchia and Barlier data to compute the coefficients associated with anomalous oxygen species and have excluded the summer-highaltitude Jacchia and Burlier data in determining the standard themospheric constituents.

\section{A.4. Distribution Package and Access}

The present NRLMSISE-00 distribution package is an ASCI file containing the model source, a test driver, and the expected output of the test driver. Users may acquire the file vid two methods:

(1) download from our website: http:/uap-www.nrlnavy.mil/models_web/msis/msis_home.htm (2) send e-mail to NRLMSISE-00@uap2.nnl.navy.mil (no subject or message), which will result in a reply with the file as an attachment.

\section{References}

Aikin, A. C., Hedin, A. E., Kendig, D. J., and Drake, S., Themospheric Molecular Oxygen Measurements Using the Ultraviolet Spectrometer on the Solar Maximum Mission Spacecraft, J. Geophys. Res., 98, 17607-13, 1993.

Arduini, C., U. Ponzi, G. Laneve, "Tidal Analysis of the San Marco V and Sar Marco III: Density Data in Equatorial Orbit," J. Amos. Solar-Terr. Phys., 59 (13), 1491-1503, 1997.

Banks, P. M. and Kockarts, G., Aeronomy, Part B, Academic Press, New York, 1973. 
Bass, J. N., M. J. Kendra, J. M. Griffin, D. R. Larson, N. Ericson, and T. Killeen, Computer Efficient Models of Thermospheric Density ard Composition: Application of Satellite Data in Near Real Time - Final Report, Report No., PL-TR-96-2150, (Phillips Laboratory, Hanscom AFB, MA, 1996).

Barlier, F., Berger, C., Falin, J. L., Kockarts, G., and Thuillier, G., A thermospheric model based on satellite drag dara, Ann. Geophys.. 34, 9-24, 1978.

Boudon, Y., F. Barlier, A. Bemard, R. Juillerar, A. Mainguy, "Synthesis of Flight Results of the CACTUS Accelerometer for Accelerations Below 10-9g," Acta Astronaut, 6 (1 1) 1387 $1398,1979$.

Buonsanto, M. J., and Pohlman, L. M., Climatology of neutral exospheric temperature above Millstone Hill, J. Geophys. Res., 103, 23381-23392, 1998.

Champion, K. S. W., and F. A. Marcos, "The Triaxial-Accelerometer System on Atmosphere Explorer," Radio Science, 8(4), 297-303, 1973.

Cotton, D. M., G. R. Gladstone, and S. Chakrabarti, Sounding Rocket Observation of a Hot Atomic Oxygen Geocorona, J. Geophys. Res, 98, 21651-7, 1994.

Goncharenko, L. P. and Salah, J. E., Climatology and variability of the semidiumal tide in the lower themosphere over Millstone Hill, J. Geophy's. Res., 103, 20715-20726, 1998.

Gonzalez, S. A., and M. P. Sulzer, Detection of $\mathrm{He}^{+}$Layering in the Topside Ionosphere Over Arecibo During Equinox Solar Minimum Conditions, Geophys. Res. Lett., 23(18), 2509 12,1996 .

Hedin, A. E., Extension of the MSIS thermosphere model into the middle and lower atmosphere, J. Geophys. Res., 96, 1159-1172, 1991.

Hedin, A. E., Hot oxygen geocorona as inferted from neutal exospheric models and mass spectrometer measurements, J. Geophys. Res., 94, 5523-5529, 1989.

Hedin, A. E., High altitude armospheric modeling, NASA Tech. Memo. $100707,1988$.

Hedin, A. E., MSIS-86 thermospheric model, J. Geophys. Res., 92, 4649-4652, 1987.

Hedin, A. E., J. E. Salah, J. V. Evans, C. A. Reber, G. P. Newton, N. W. Spencer, D. C. Kayser, D. Alcayde, P. Bauer, L. Cogger, and J. P. McClure, A Global Themospheric Model 
Based on Mass Spectrometer and Incoherent Scatter Data MSIS 1. N2 Densiry and Temperature, J. Geophys. Res., 82 (16), 2139-2147, 1977.

Jacchia, L., New Static Models of the Thermosphere and Exosphere with Empirical Temperature Profiles," Smithsonicun Astrophys. Observatory Special Rep. No. 313, May 6, 1970.

Kayser, D. C., Solar flux variation of the themospheric molecular oxygen density, J. Genphys. Res., $85,695-702,1980$.

Keating, G. M., Leary, J. C., Green, B. D., Uy, O. M., Benson, R. C., Erlandson, R. E., Phillips, T. E., Lesho, J. C., and Boies, M. T., Neutral and ion drag effects near the exobase: MSX satellite measurements of $\mathrm{He}$ and $\mathrm{O}^{+}, \mathrm{AAS} 97-634$ and in Astrodynamics 1997, Adv. Astronaut. Sci., Part 1. 97, ed. by F. Hoots, B. Kaufman, P. Cefola, and D. Spencer, Amer. Astronaut. Soc., San Diego, 549-556, 1998.

Knowles, S. H., J.M. Picone, S. Thonnard, A. Nicholas, The Effect of Atmospheric Drag on Satellite Orbirs During the Bastille Day Event, Solar Physics, submitted, 2001.

Lean, J. L., O. R. White, W. C. Livingston, and J. M. Picone, "Variability of a Composite Chromospheric Iradiance Irdex During the 11-Year Activity Cycle and Over Longer Time Periods," J. Geophys. Res., 105 (A6). 10645-58 (2001).

Litvin, A., W. L. Oliver, J. M. Picone, M. J. Buonsanto, The upper armosphere during 5-11 June 1991,"J. Geophys. Res. 105(A6), 12789-96 (2000).

Marcos, F. A., Hedin, A. E., Liu, J., Bass, J. N., and Baker. C. R., Operational satellite drag model standards, AlAA 95-055I, $33^{\text {nd }}$ Aerospace Sciences Meeting \& Exhibir, Reno. NV. 1995.

Marcos, F. A., M. J. Kendra, J. M. Griffin, J. N. Bass, D. R. Larson, and J. J. F. Liu, "Precision Low Earth Orbit Determination Using Atmospheric Density Calibration," AAS 97-631. and in Astrodynamics 1997: Advances in the Astronoutical Sciences, Vol. 97(I), ed. by F. Hoots, B. Kaufman, P. Cefola, and D. Spencer, Am. Astronaut. Soc.. San Diego, 501 $513,1998$.

Meriwecher, J.W., and C. S. Gardner, A review of the mesosphere inversion layer phenomenon, J. Geophys. Res., 105(D10), 12405-16, May 27, 2000. 
Melendez-Alvira, D. J., Picone, J. M., Kelley, O. A., Zhou, Q., and Sulzer, M. P., Histograms of Arecibo World Days measurements and linear-H fits between 1985 and 1995, NRL Memo. Rep. NRL/MR 7640-98-831, 1998.

Mejer, R. R., J. M. Picone, D. P. Drob, and R. G. Roble, Similarity Transformation-Based Analysis of Atmospheric Models, Data, and Inverse Remote Sensing Algorithms, $J$. Geophys. Res., to be published (2001).

Neal, H. L., S. L. Coffey, and S. Knowies, "Maintaining the Space Object Catalog with Special Perturbations," AAS 97-687, and in Astrodynomics 1997: Advances in the Astronautical Sciences, Vol. 97(2), ed. by F. Hoors, B. Kaufman, P. Cefola, and D. Spencer, A.m. Astronaut. Soe., San Diego, 1349-60, 1998.

Nicholas, A., J. M. Picone, S. E. Thonnard, R. R. Meier, K. F. Dymond, and D. P. Drob, "A Methodology for using Optimal MSIS Parameters Retrieved from SSULI Data to compute Sarellite Drag on LEO Objects," J. Armos. Solar-Terr. Phys. 62, 1317-26, 2000.

Oliver, W. L., Hot oxygen and the ion energy budget, J. Geophys. Res., 102(A2), 2503-11, 1997.

Oliver, W. L., and J. Schoendorf, Variations of hot $O$ in the thermosphere, Geophy. Res. Lett. 26(J8), 2829-32, 1999.

Pavlov, A. V., Thermal Diffusion in the Upper Atmosphere of the Earth, Geomagnetism and Aeronomy, 19(6), 707-11 (1979).

Press, W. H., Teukolsky, S. A., Vetterling, W. T., and Fannery, B. P., Numerical Recipes: The Arr of Scientific Computing, Cambridge University Press, New York, 1992.

Rhoden, E. A., I. M. Forbes, and F. A. Marcos, The influence of geomagnetic and solar variabilities on lower thermosphere density, J. Aimos. Solar-Terr. Phys. 62, 999-1013, 2000.

Schoendorf, J., L. A. Young, and W. L. Oliver, Hor oxygen profiles for incoherent scatter radar analysis of ion energy balance, J. Geophys. Res., 105(A6), 12823-12832, June 1, 2000.

U.S. Standard Atmosphere, 1976, U.S. Government Printing Office. Washington, D.C., 1976. Walker, J. C. G., Analytic Representarion of Upper Atmosphere Densities Based on Jacchia's Static Diffusion Models, J. Ámos. Sci., 22, 462-3 (1965).

Yee, J. H., J. W. Meriwether, Jr, and P. B. Hays, Detection of a Corona of Fast Oxygen Atoms during Solar Maximum, J. Geophys. Res., 85(A7), 3396-3400, July 1, 1980. 


\section{Figures}

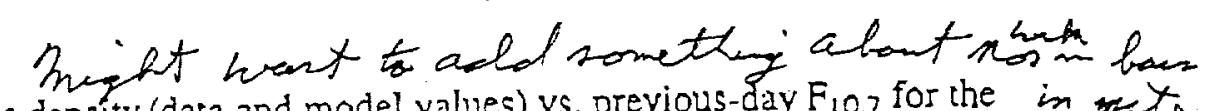

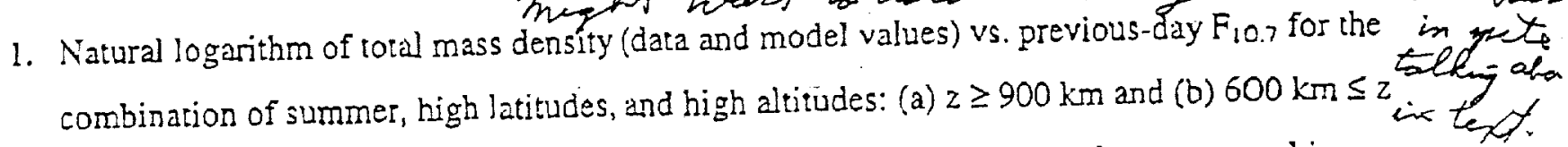
$\leq 900 \mathrm{~km}$. The density values are nomalized to the Jacchia-70 model and are averaged in bins of $10 F_{10.7}$ units. Vertical bars correspond to the $\pm 1 \sigma$ range of Jacchia data within each bin; the Jacchia-70 model values fall on the horizontal line at 0.0. NRLMSISE-00 comesponds to the solid curve and MSISE- 90 to the dashed curve.

2. Same as Figure 1 for the combination of winter, high latitudes, and high altitudes: (a) $z \geq$ $900 \mathrm{~km}$ and (b) $600 \mathrm{~km} \leq \mathrm{z} \leq 900 \mathrm{~km}$.

3. (2) Lower thermospheric profile of $\left[\mathrm{O}_{2}\right]: \log _{2}$ of ratio to MSYSE-90 values. A veraging interval: $2 \mathrm{~km}$. Solid curve: NRIMSISE-00 values. Letters and symbols identify individual data sources (Acronyms: Atmospheric Explorer missions, AE; Solar Maximum Mission, SMM) - Solar UItraviolet Occulcation: (K) SMM, (A) AE-C, $100 \mathrm{~km}$, (B) AE-C, $130 \mathrm{~km}$, (V) AE-C, $150 \mathrm{~km}$, (D) AE-E, $100 \mathrm{~km}$, (E) AE-E, $130 \mathrm{~km}$, (F) AE-E, $150 \mathrm{~km}$, channel 19 , (W) AE-E, $150 \mathrm{~km}$, channel 06, (M) Rocker; Mass Spectrometer: (C) AE-C, (G) AE-D, (J) AE-E, ( + Rockel.

(b) Natural logarithm of lower themospheric $\left[\mathrm{O}_{2}\right]$ vs. mean $F_{10.7}$, averaged within bins of 10 flux units. The plot shows the mean of data values normalized by MSISE-90. Vertical bars correspond to the $\pm 1 \sigma$ range of normalized $\left[\mathrm{O}_{2}\right]$ values within each bin. MSISE-90 corresponds to the horizontal line at 0.0 .

(c) Same as (b), bur with data normalized to NRLMSISE-00, which corresponds to the horizontal line at 0.0 .

4. $T_{=x}$ vs. $F_{10.7}$ (previous day), averaged over bins of 10 flux units: (a) Millsione Hill dara (198197) and (b) Arecibo data (1985-95). The quantities plotted are, respectively, differences of data (vertical bars) and of NRIMSISE-00 model valuès (solid curve) from MSISE-90 (horizontal line at 0.0 ).

5. Exospheric temperaure difference between NRIMSISE-00 and MSISE-90, averaged over longitude and time, as a function of latitude and $\left(F_{10.7}\right\rangle$. 
6. Examples of temperature profiles resembling mesosphere inversion layers. produced by NRLMSISE-00 (solid curve) and MSISE-90 (dashed curve). Conditions: (a) local time 2100 $\mathrm{hr}$ and (b) local time $1000 \mathrm{hr}$, both at $0 \mathrm{UT}$, day 90 , latitude $5^{\circ}$. longinude $315^{\circ}, \mathrm{F}_{10.7}=\left\langle\mathrm{F}_{10.7}\right\rangle$ $=150, A_{p}=4$. 
Introduction to tables in AGU Electronic Dalaset Archive:

\section{Tables of Empirical Model Comparisons with the NRLMSIS Database}

The following tables compare all data sets in the NRLMSIS database to the corresponding values of several empirical models: NRLMSISE-00 (M00), MSISE-90 (M90), and Jacchia-70 (J70). The tables provide values of the bias or mean residual ("MEAN") and standard deviation ("SD") as functions of geomagnetic activity (quiet, high, and all levels). The tables include both the model generation database and the complete, newly added data sets (designated by footnotes). For remperature $T$, the tables show a mean residual $\equiv\left\langle T_{i}(d a t a)-T_{i}\right.$ (model $\left.)\right\rangle$ and $\sigma \equiv\left(\left\langle\left[T_{i}(\text { data })-T_{i}(\text { model })\right]^{2}\right\rangle-\beta^{2}\right)^{1 / 2}$ in units of Kelvin. For species number density and total mass density, we have expressed the mean residual as an average fractional density bias $\beta=$ $\exp \left(\log _{e}\left(\rho_{i}\right.\right.$ (data) $\left./ p_{i}(\operatorname{model})\right\rangle-1$, and have computed the standard deviation as $\sigma=$ $\left(\left(\log _{e}{ }^{2}\left\{\rho_{i}(\text { data }) / \rho_{i}(\operatorname{mode} l)\right]\right\rangle-\beta^{2}\right)^{1 / 2}$.

The accompanying paper, "NRIMSISE-00 Empirical Model of the Atmosphere: Statistical Comparisons and Scientific Issues," (J. M. Picone, A. E. Hedin, D. P. Drob, and A. C. Aikin, J. Geophys. Res. $x \times x, 200 x$ ), and references therein provide background on the data sets. Accompanying the data set same is a descriptor; abbreviations include "accel" (acceleroneter), "drag" (drag from orbit determination), "NMS" (neutral mass spectrometer), "IMS" (ion mass spectromerer), "ISR" (incoherent scatter radar), and "UV occ" (solar ultraviolet occultation). 
Figures 1-2

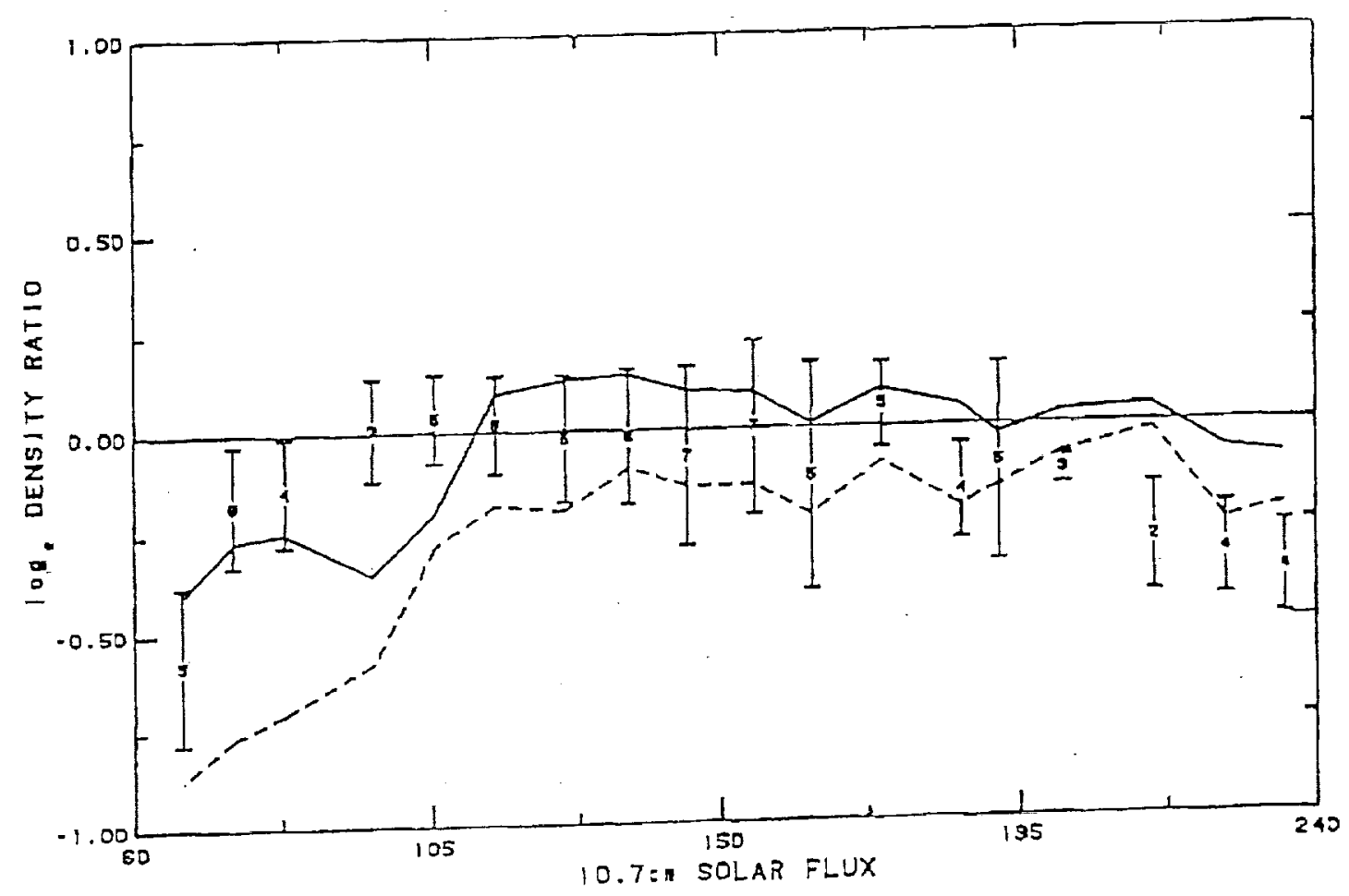

Figure 1(a) 


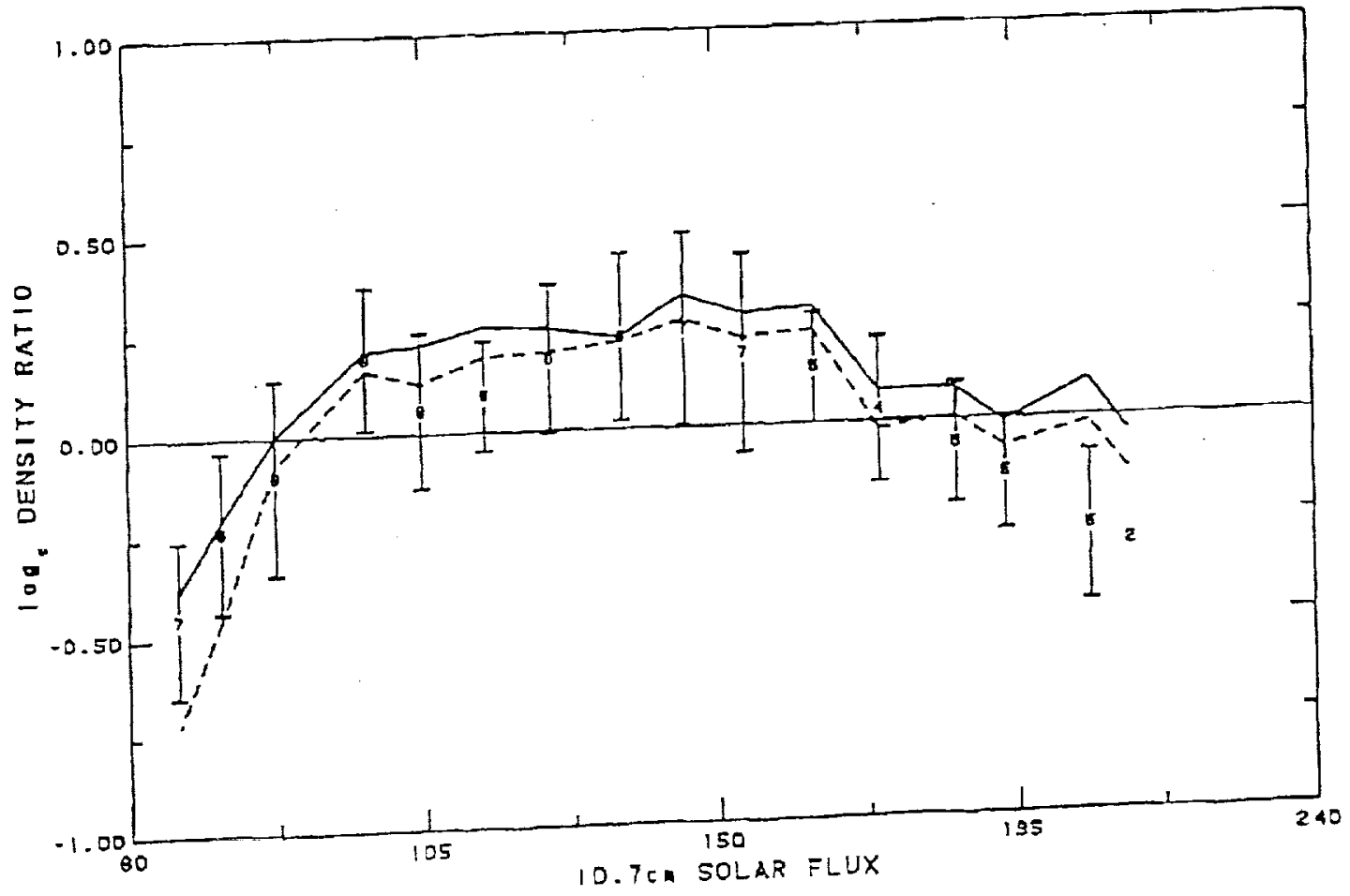

Figure 1(b) 


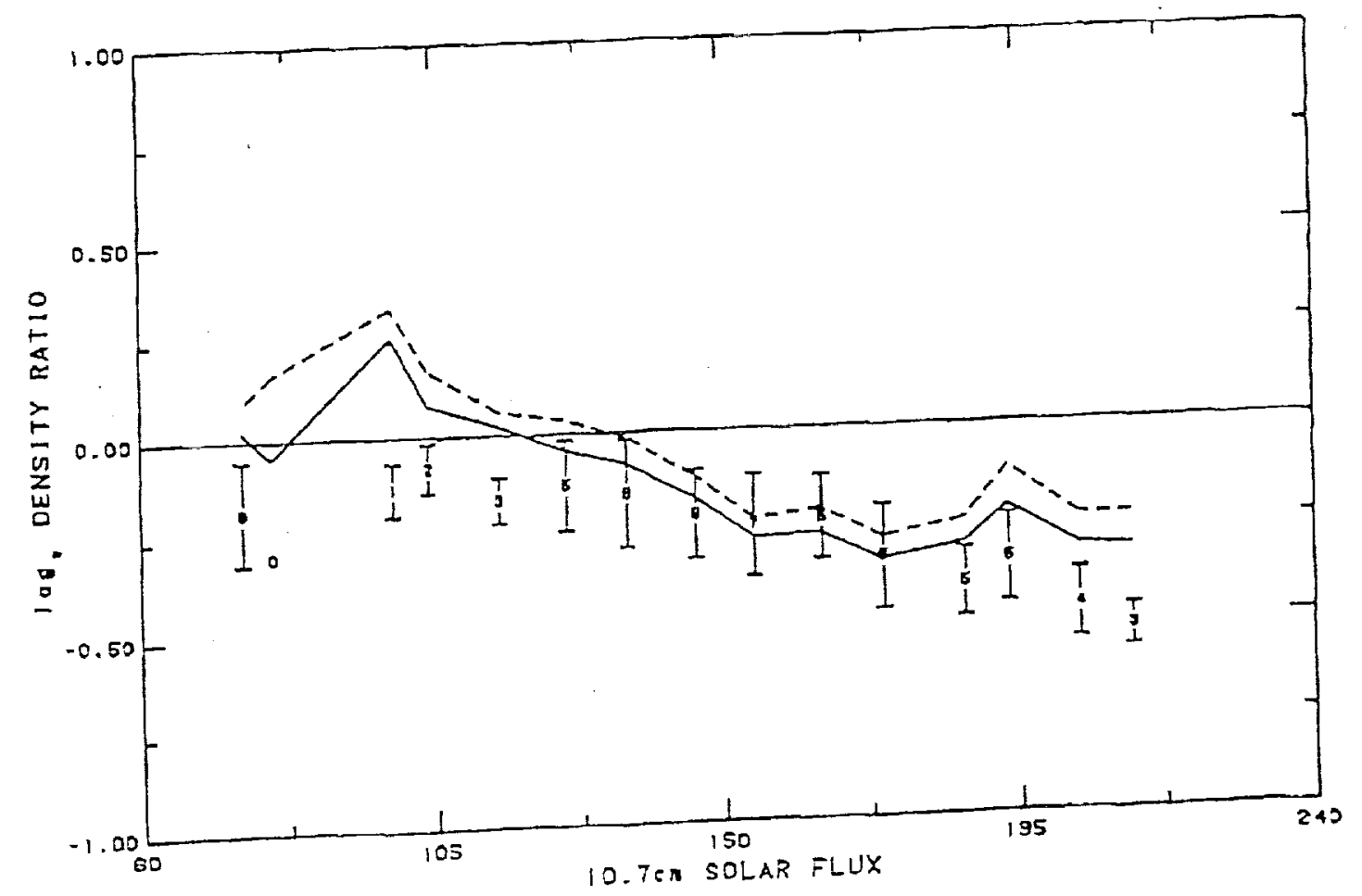

Eigure 2(3) 


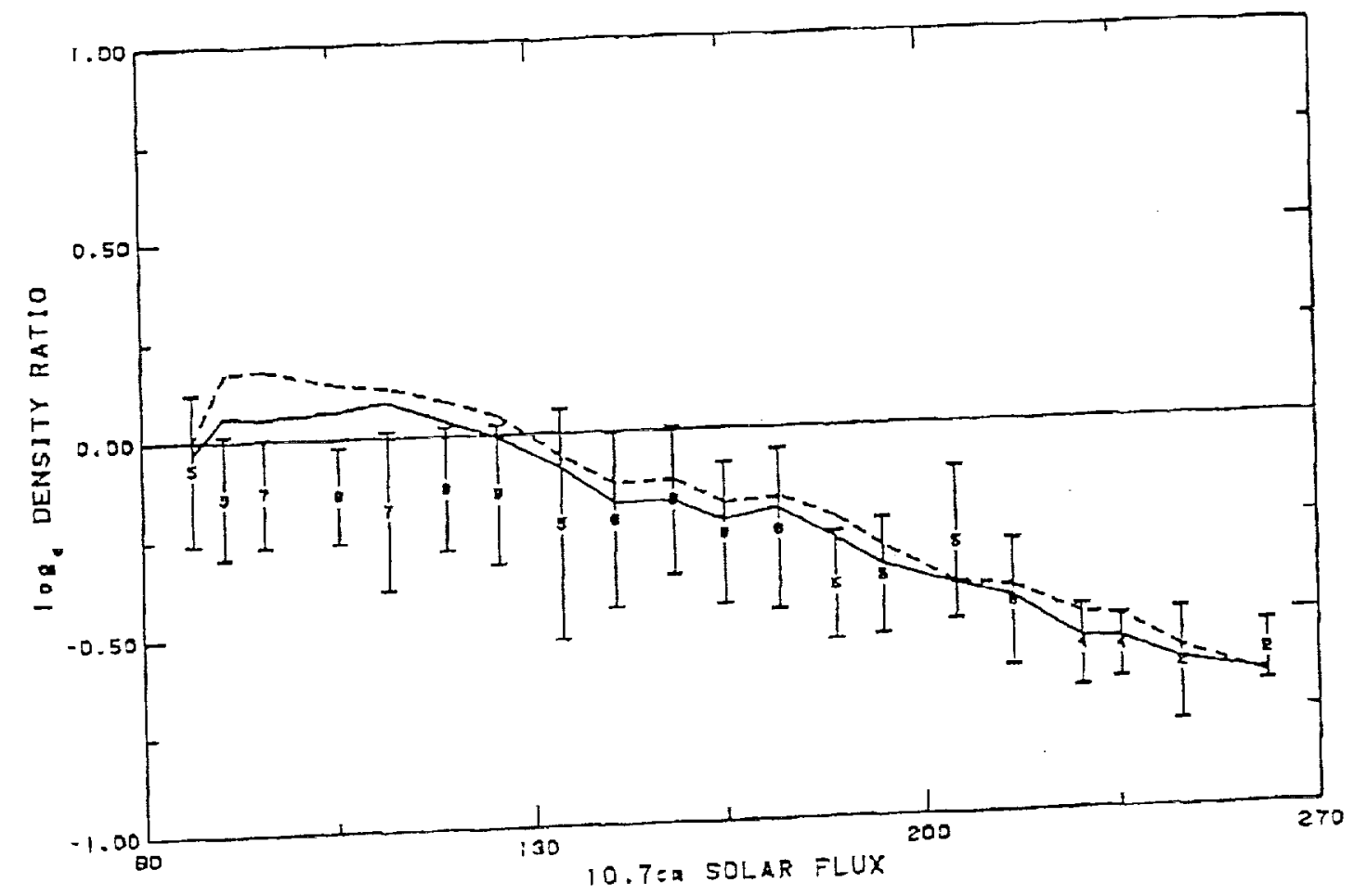

Eigure 2(b) 


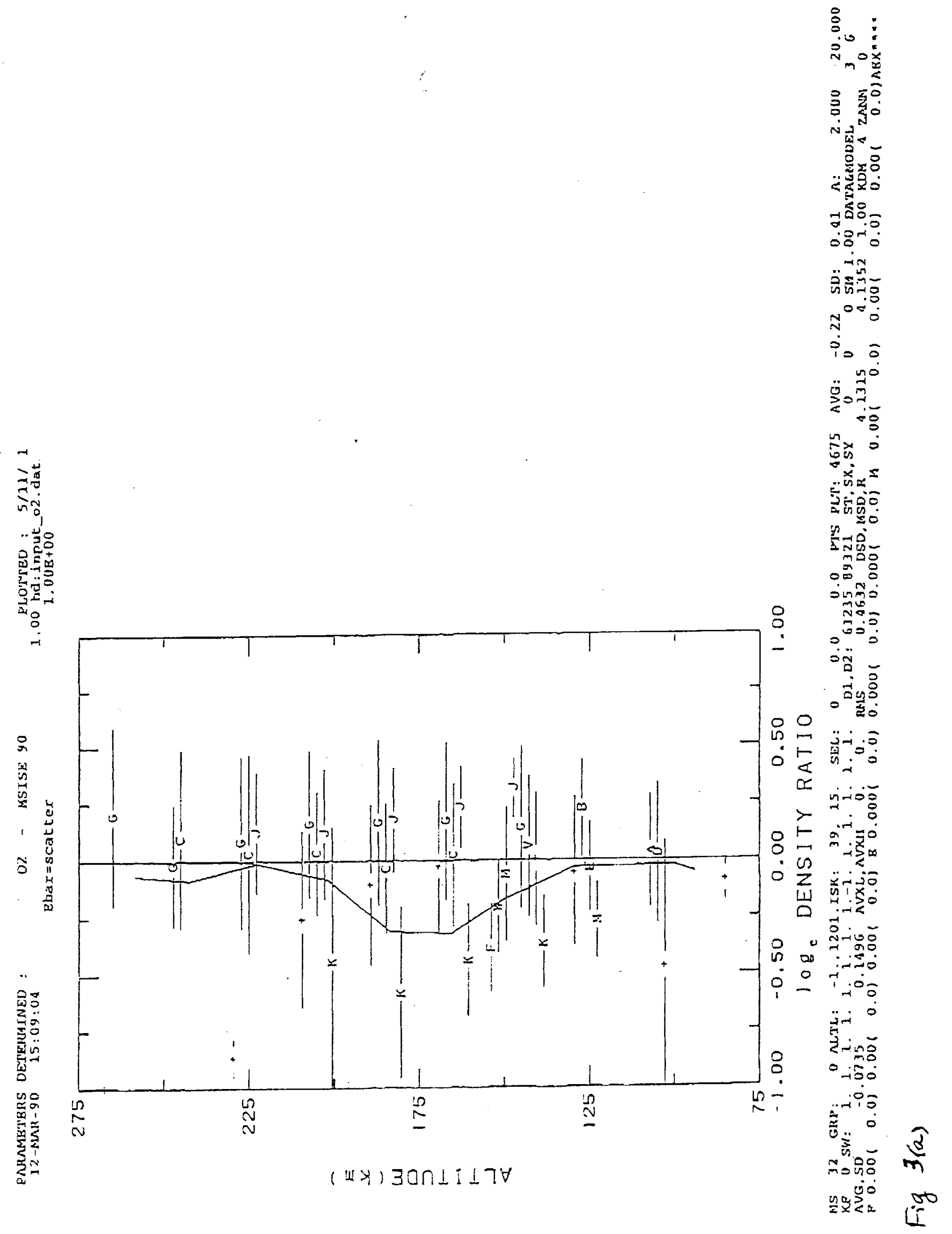




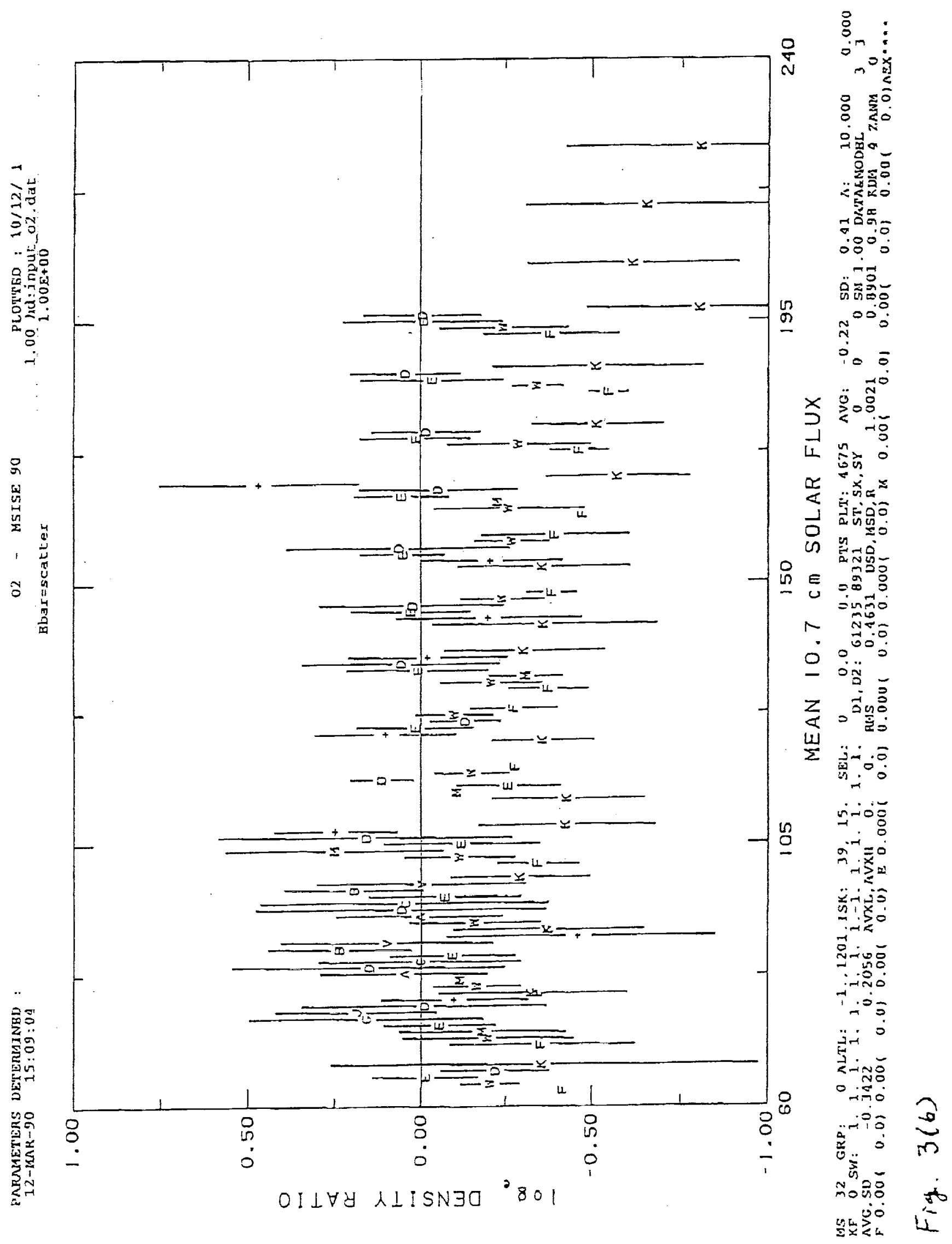




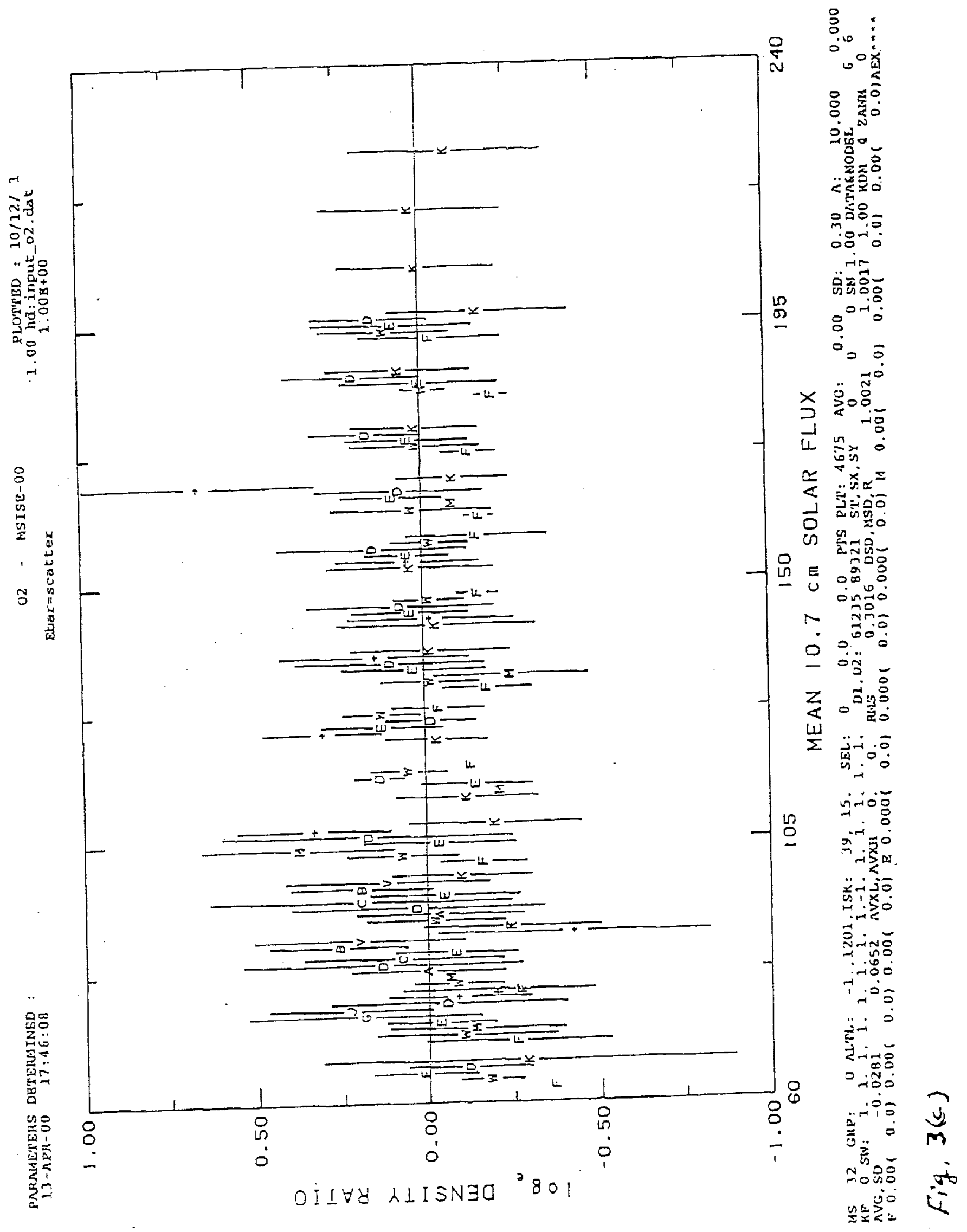




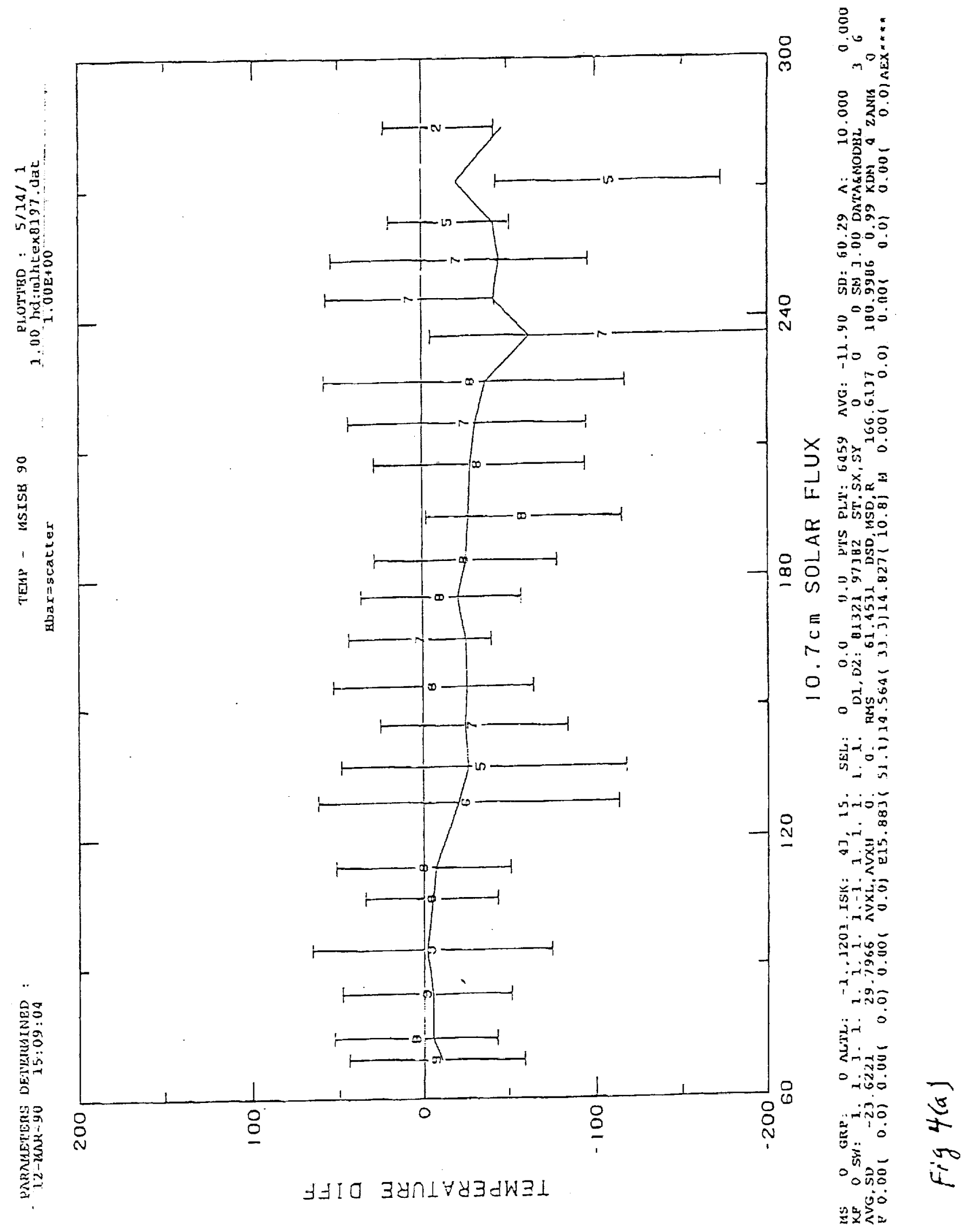




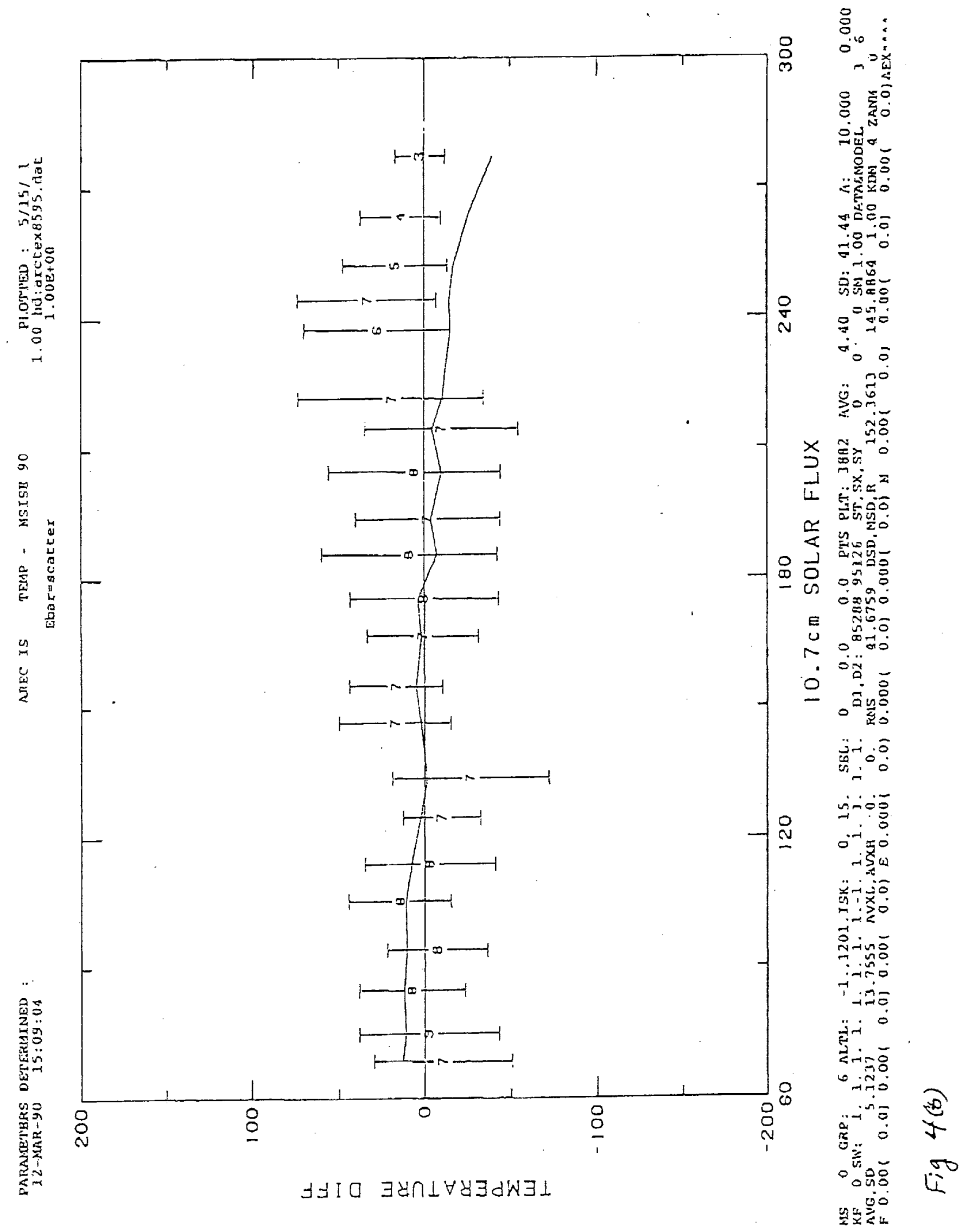




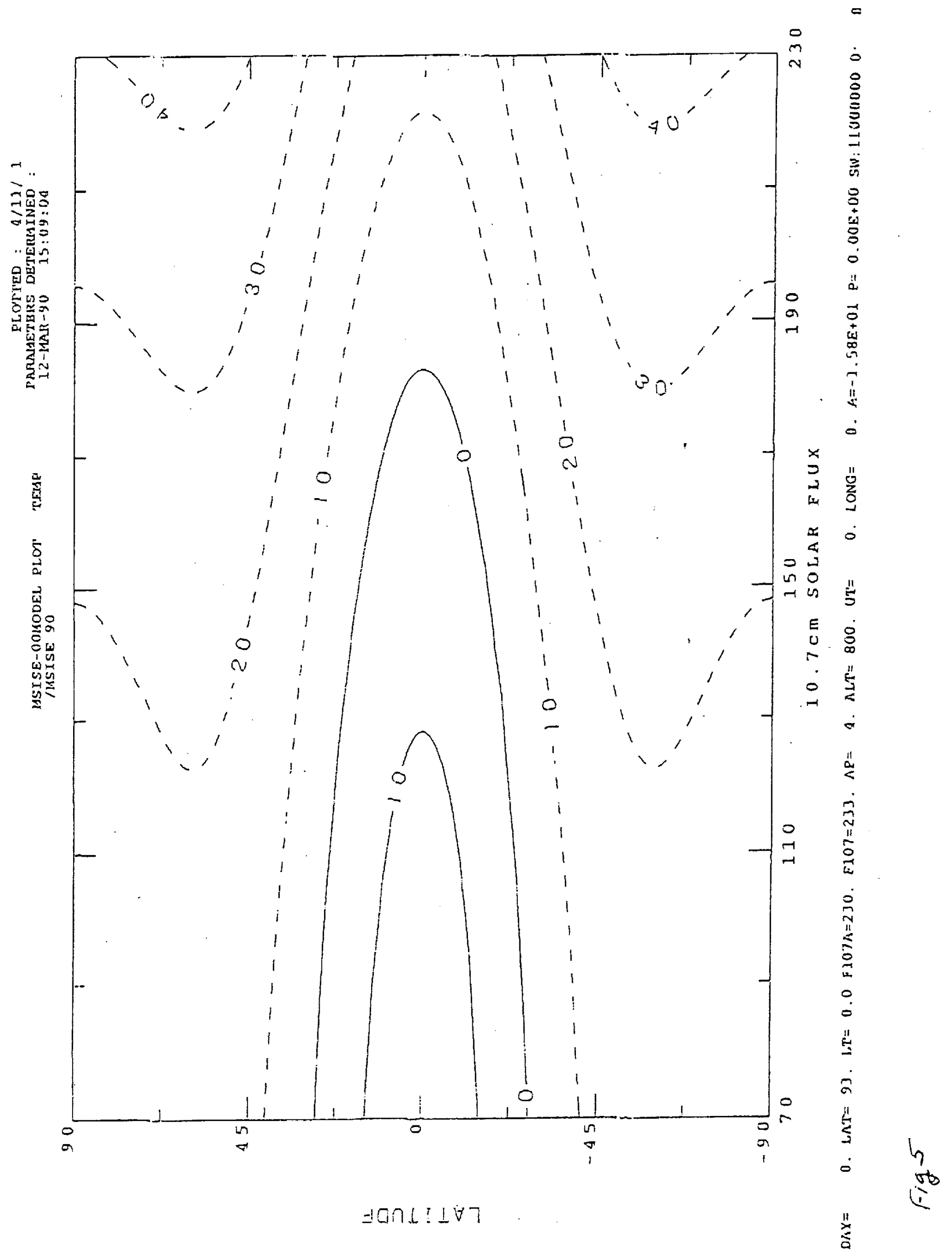




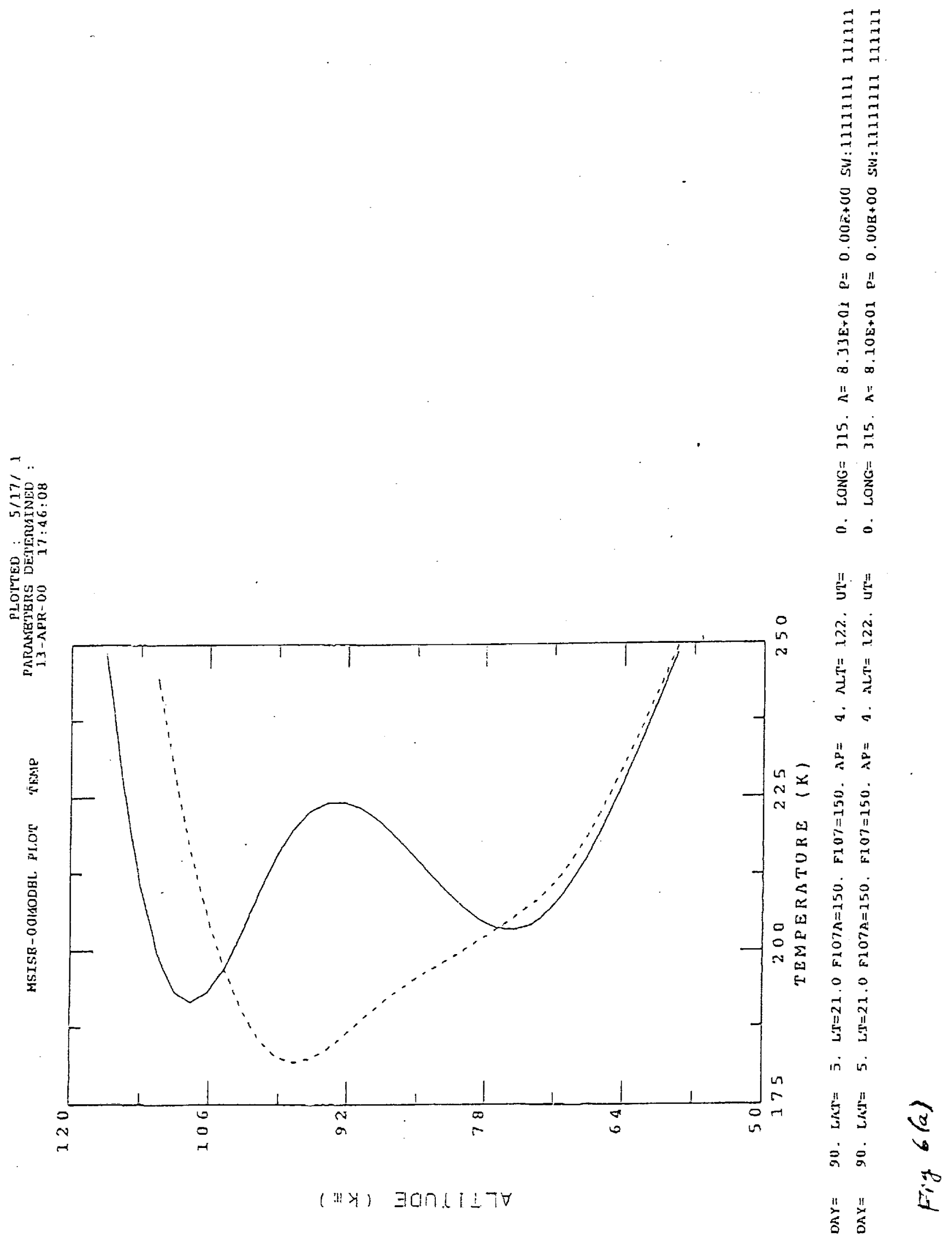




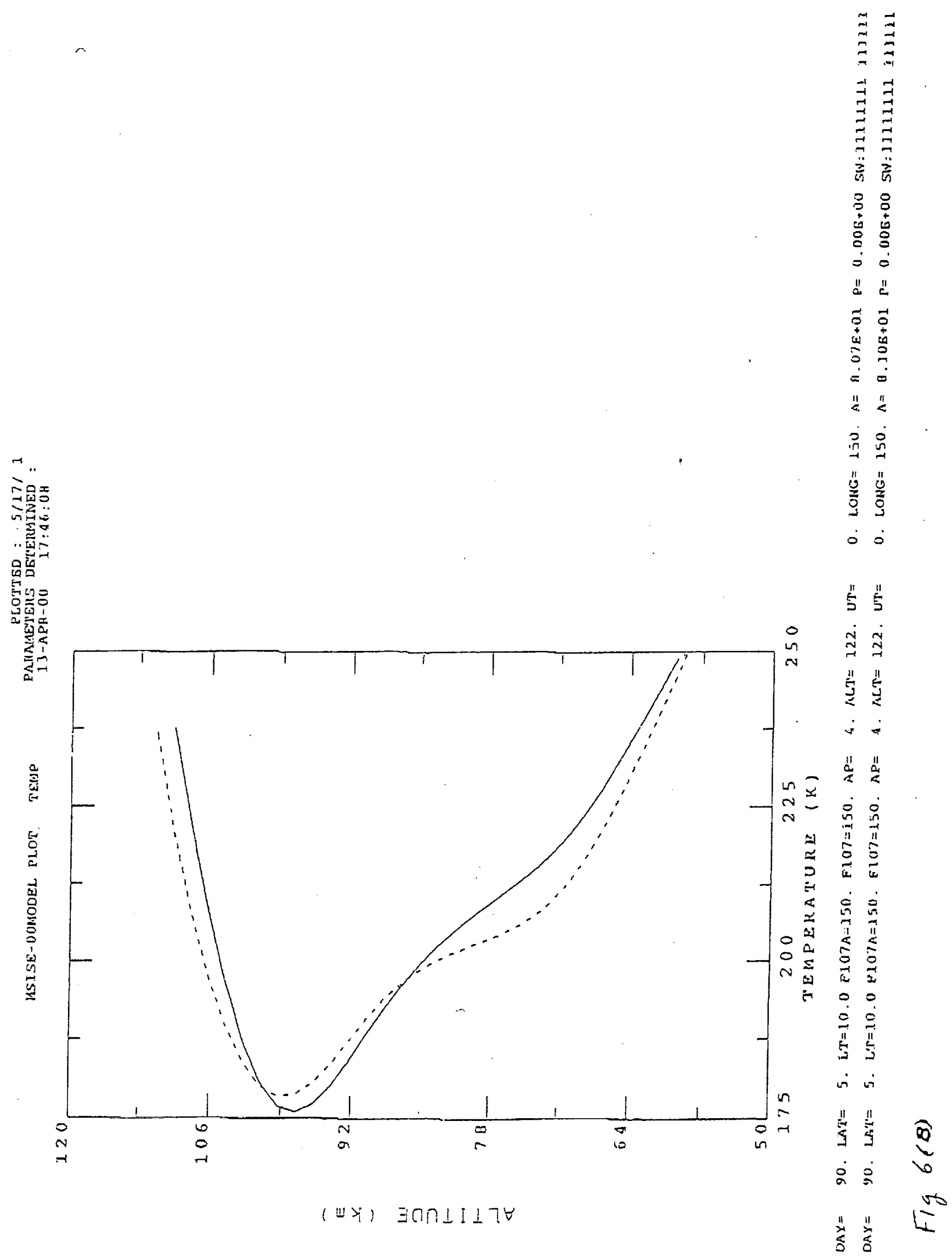


Table $1(3)$. Comparison of mocieis to drag, acceleromerer, and rocket database on tocai maso censicy for guiet geomagnetic activity $\left(A_{F} \leq 10\right)$

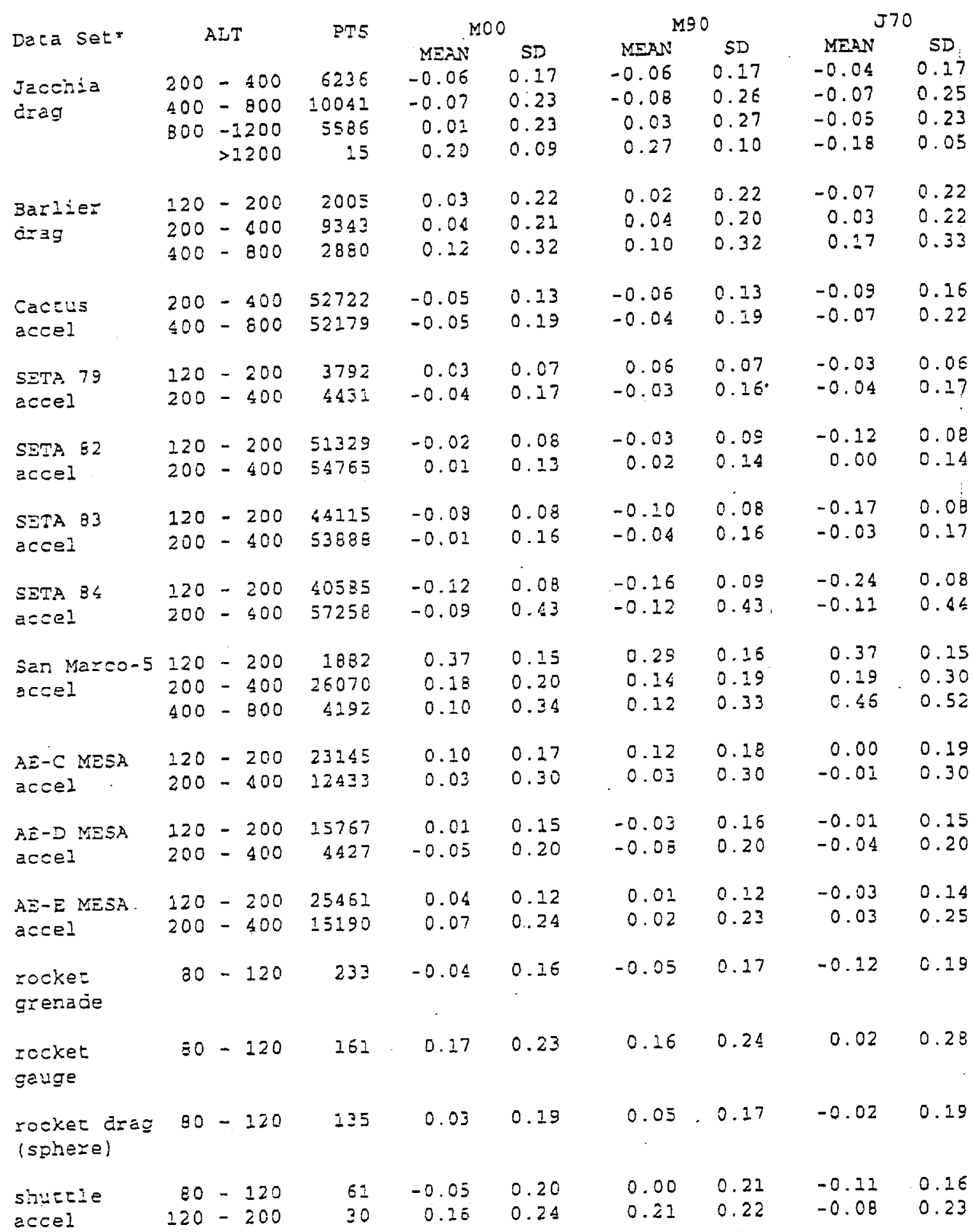

- Complete dzag and accelerometer date sers used for calcularions 
Table $1(b)$. Comparison of models to drag, accelerometer, and rocket database on toral mass density for high geomagnetic activity $\left(A_{D} \geq 50\right)$

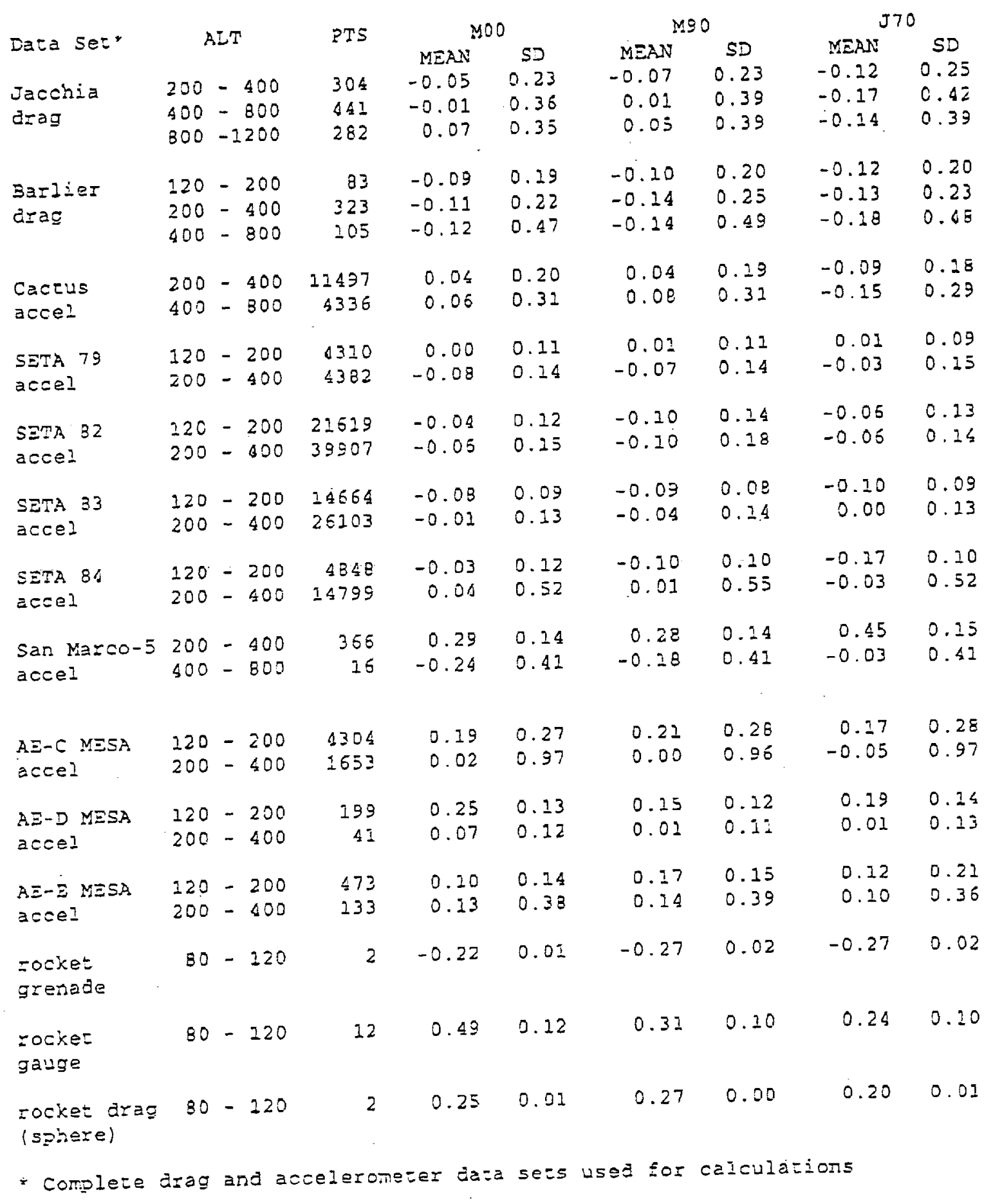


Table $i(c)$. Comparison of models to drag, accelerometer, and rocket dacabase on coial mass density ocrose all geomagnetic activizy levels

\begin{tabular}{|c|c|c|c|c|c|c|c|c|c|}
\hline \multirow{2}{*}{ Deta Setr } & \multirow{2}{*}{\multicolumn{2}{|c|}{$A L T$}} & \multirow{2}{*}{ PTS } & \multicolumn{2}{|c|}{ MOO } & \multicolumn{2}{|c|}{ M9O } & \multicolumn{2}{|c|}{570} \\
\hline & & & & MEAN & $S D$ & $M \equiv A N$ & SD & $M E A N$ & SD \\
\hline $\begin{array}{l}\text { Jacchia } \\
\text { drag }\end{array}$ & $\begin{array}{l}200 \\
400\end{array}$ & $\begin{array}{l}-800 \\
-800\end{array}$ & $\begin{array}{l}10456 \\
16021\end{array}$ & -0.07 & 0.17 & -0.06 & $\begin{array}{l}0.17 \\
0.27\end{array}$ & $\begin{array}{l}-0.07 \\
-0.09\end{array}$ & $\begin{array}{l}0.29 \\
0.28\end{array}$ \\
\hline & $\begin{array}{l}500 \\
800\end{array}$ & $\begin{array}{l}-800 \\
-1200\end{array}$ & $\begin{array}{r}16021 \\
9373\end{array}$ & $\begin{array}{r}-0.08 \\
0.02\end{array}$ & $\begin{array}{l}0.25 \\
0.24\end{array}$ & $\begin{array}{r}-0.07 \\
0.04\end{array}$ & $\begin{array}{l}0.27 \\
0.27\end{array}$ & $\begin{array}{l}-0.09 \\
-0.07\end{array}$ & $\begin{array}{l}0.28 \\
0.25\end{array}$ \\
\hline & & $>1200$ & 24 & 0.22 & 0.12 & 0.30 & 0.11 & -0.20 & 0.13 \\
\hline $\begin{array}{l}\text { BarlieI } \\
\text { arag }\end{array}$ & 120 & -200 & 3285 & 0.01 & 0.22 & 0.00 & 0.23 & -0.08 & 0.22 \\
\hline $\begin{array}{l}\text { Cactus } \\
\text { accel }\end{array}$ & 800 & $\begin{array}{l}-500 \\
-800\end{array}$ & 52506 & -0.05 & $\begin{array}{l}0.24 \\
0.20\end{array}$ & -0.04 & 0.13 & $\begin{array}{l}-0.09 \\
-0.10\end{array}$ & 0.17 \\
\hline & & & & & & -0.01 & 0.20 & & 0.22 \\
\hline accel & 200 & -400 & $\begin{array}{l}30612 \\
32067\end{array}$ & $\begin{array}{r}0.01 \\
-0.07\end{array}$ & $\begin{array}{l}0.10 \\
0.15\end{array}$ & $\begin{array}{r}0.04 \\
-0.05\end{array}$ & 0.09 & $\begin{array}{r}0.00 \\
-0.04\end{array}$ & 0.09 \\
\hline & & & & -0.04 & 0.10 & -0.00 & 0.14 & & \\
\hline accel & 200 & $-\$ 00$ & $5: 652$ & -0.03 & 0.14 & $\begin{array}{l}-0.06 \\
-0.04\end{array}$ & $\begin{array}{l}0.11 \\
0.15\end{array}$ & $\begin{array}{l}-0.20 \\
-0.04\end{array}$ & 0.10 \\
\hline $\begin{array}{l}\text { SETA } 53 \\
\text { accel }\end{array}$ & 120 & -200 & 57350 & -0.03 & 0.09 & & 0.15 & & 0.14 \\
\hline ccel & 200 & -400 & 54761 & -0.01 & 0.16 & $\begin{array}{l}-0.10 \\
-0.04\end{array}$ & $\begin{array}{l}0.09 \\
0.16\end{array}$ & $\begin{array}{l}-0.15 \\
-0.02\end{array}$ & 0.09 \\
\hline & $\begin{array}{l}200 \\
400\end{array}$ & -400 & $\begin{array}{r}2935 \\
41075\end{array}$ & $\begin{array}{l}0.35 \\
0.21\end{array}$ & 0.13 & & & & \\
\hline & 400 & -300 & 7285 & $\begin{array}{l}0.21 \\
0.10\end{array}$ & $\begin{array}{l}0.18 \\
0.32\end{array}$ & & & & \\
\hline $\begin{array}{l}A \equiv-D M E S A \\
a c c e I\end{array}$ & & & & & & 0.03 & 0.30 & -0.02 & $\begin{array}{l}0.19 \\
0.30\end{array}$ \\
\hline accel & 200 & -400 & $\begin{array}{r}28499 \\
2170\end{array}$ & $\begin{array}{r}0.01 \\
-0.05\end{array}$ & $\begin{array}{l}0.16 \\
0.20\end{array}$ & & & & \\
\hline $\begin{array}{l}A=-2=1.2 A \\
a c c e l\end{array}$ & $\begin{array}{l}120 \\
200\end{array}$ & $\begin{array}{l}-200 \\
-400\end{array}$ & $\begin{array}{l}53798 \\
24982\end{array}$ & $\begin{array}{l}0.05 \\
0.08\end{array}$ & 0.12 & & & & \\
\hline & & & & 0.08 & & 0.05 & 0.24 & 0.04 & $\begin{array}{l}0.25 \\
0.25\end{array}$ \\
\hline gzenede & 30 & -120 & 310 & -0.02 & 0.15 & -0.03 & 0.16 & -0.11 & 0.18 \\
\hline & & & & & & & & & \\
\hline gauge & 80 & 160 & 247 & 0.2 .1 & 0.24 & 0.20 & 0.25 & 0.07 & 0.27 \\
\hline & & & & & 0.31 & 0.09 & 0.27 & -0.01 & 0.29 \\
\hline (s) & & & & & & & & & \\
\hline shuttle & 80 & -120 & 238 & -0.07 & 0.19 & 0.00 & 0.20 & -0.11 & 0.27 \\
\hline accel & 220 & -200 & 52 & 0.07 & 0.23 & $0.1 \equiv$ & 0.21 & -0.11 & 0.21 \\
\hline
\end{tabular}




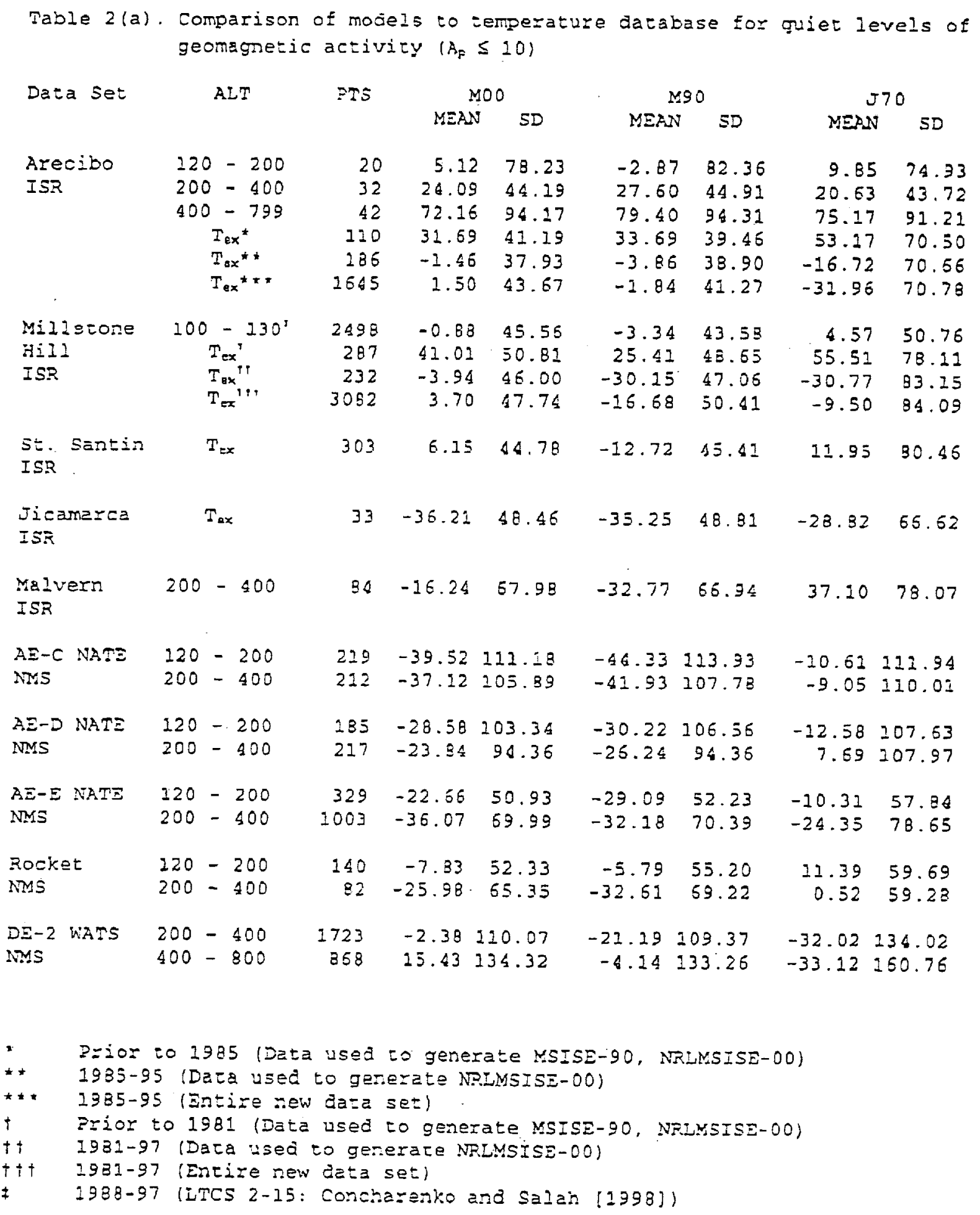




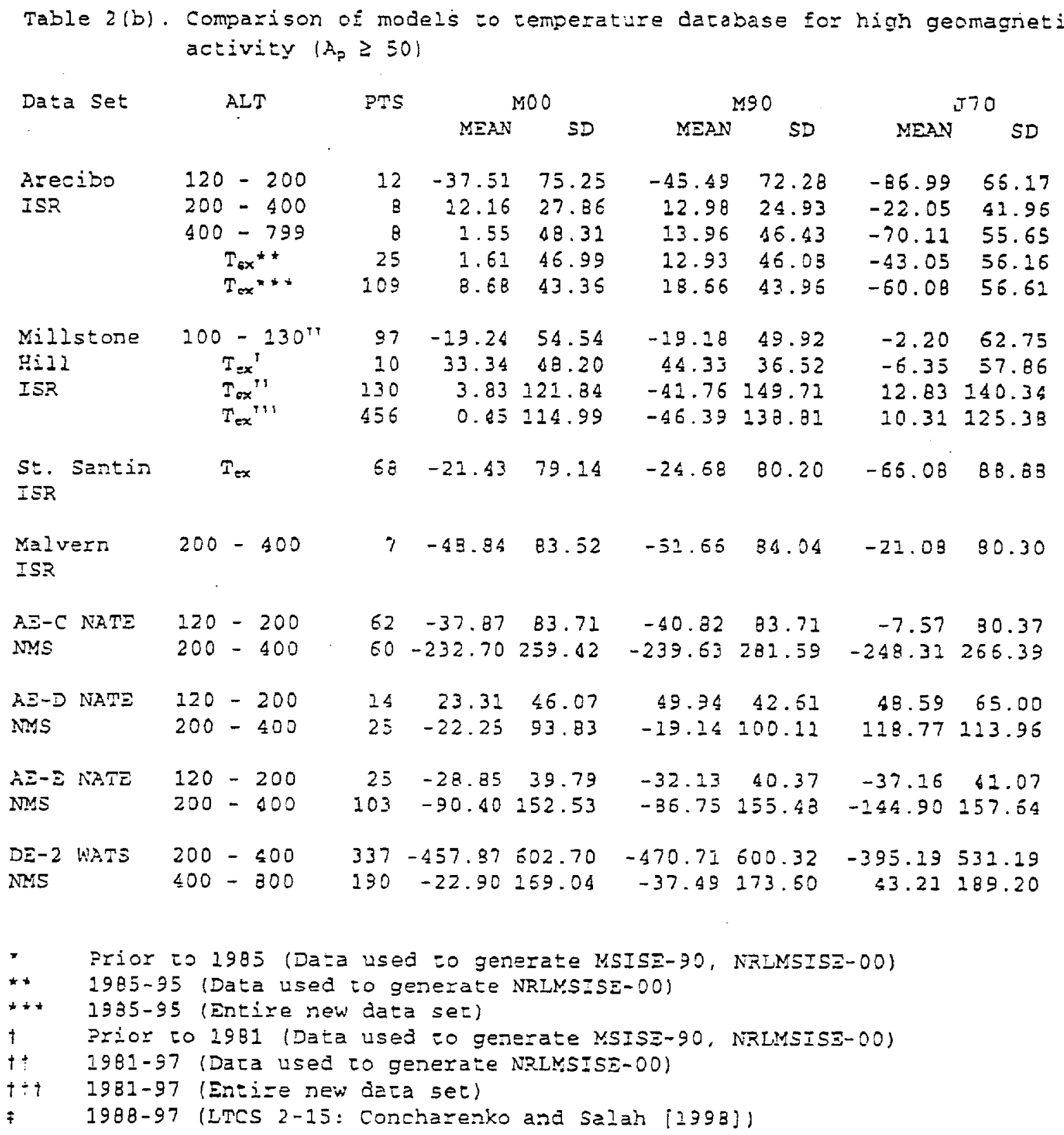




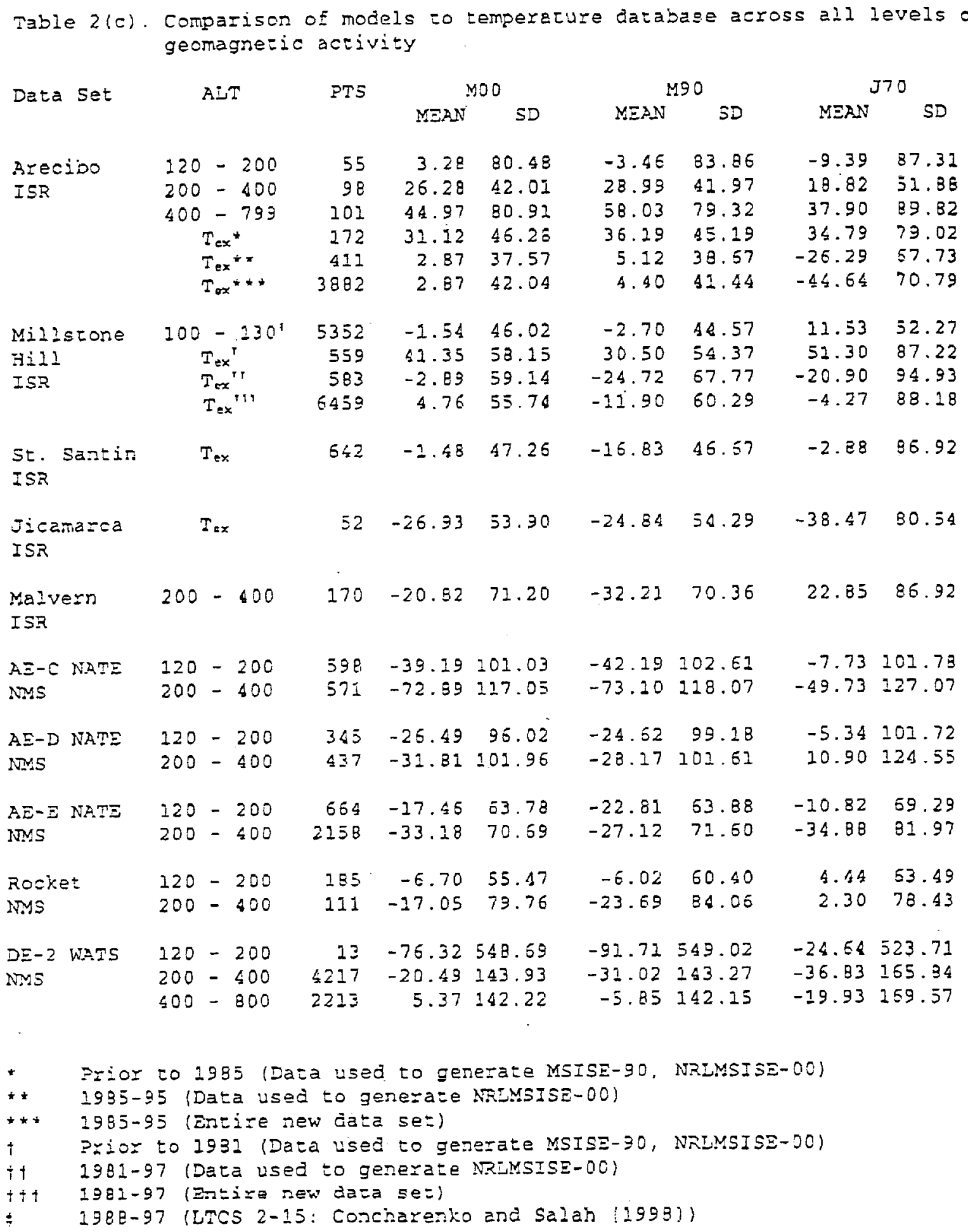


Table $3(a)$. Compazison of models $=0$ dazabase on $N_{2}$ concentration for quie: geomagnet: activity (AP $\leq 10)$

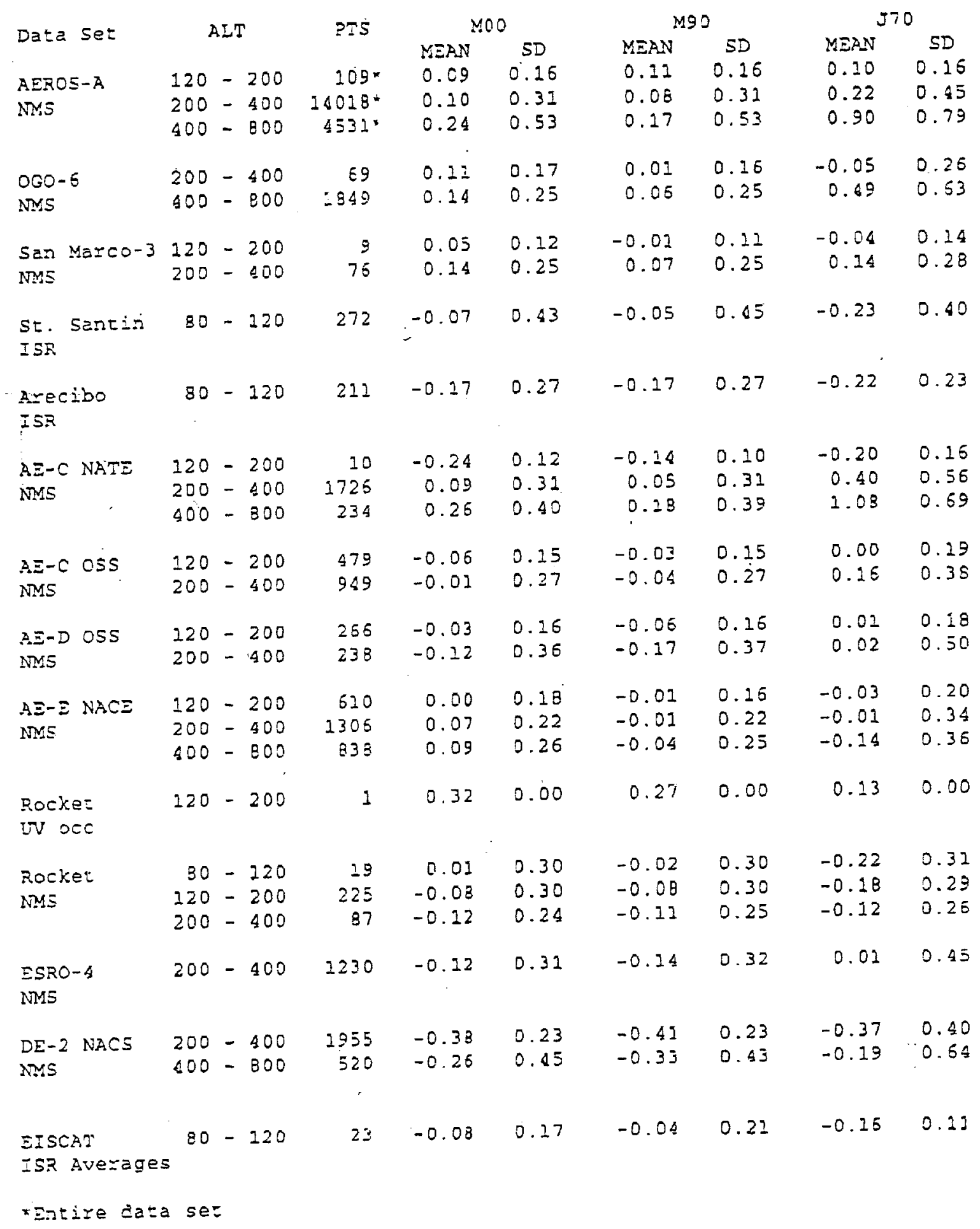




\begin{tabular}{|c|c|c|c|c|c|c|c|c|c|}
\hline \multirow[t]{2}{*}{ Data set } & \multirow{2}{*}{\multicolumn{2}{|c|}{ AIT }} & \multirow[t]{2}{*}{ PTS } & \multicolumn{2}{|c|}{ MOO } & \multicolumn{2}{|c|}{ M9O } & \multicolumn{2}{|c|}{370} \\
\hline & & & & MEAN & $S D$ & MEAN & SD & MEAN & SD \\
\hline AEROS - & 200 & -400 & $3090^{\circ}$ & -0.22 & 0.86 & -0.21 & 0.86 & 0.02 & 0.92 \\
\hline NMS & 400 & -800 & $1015^{\circ}$ & -0.10 & 0.92 & -0.09 & 0,94 & 0.52 & 1.30 \\
\hline $0 G 0-6$ & 200 & -400 & 5 & 0.09 & 0.23 & 0.08 & 0.22 & -0.23 & 0.33 \\
\hline NMS & 400 & -900 & 224 & 0.51 & 0.57 & 0.39 & 0.60 & 0.79 & 0.98 \\
\hline $\begin{array}{l}\text { St. Santin } \\
\text { ISR }\end{array}$ & 80 & -120 & 30 & 0.00 & 0.36 & 0.00 & 0.35 & -0.17 & 0.31 \\
\hline $\begin{array}{l}\text { Axecibo } \\
\text { ISR }\end{array}$ & 80 & -120 & 31 & -0.25 & 0.18 & -0.26 & 0.21 & -0.29 & 0.19 \\
\hline AE-C NATE & 200 & -400 & 250 & 0.32 & 0.56 & 0.28 & 0.57 & 0.69 & 0.76 \\
\hline NMS & 400 & -800 & 12 & 0.29 & $0.7 \mathrm{E}$ & 0.35 & 0.86 & 2.79 & 0.95 \\
\hline$A \equiv-C$ OSS & 120 & -200 & 128 & 0.07 & 0.17 & 0.08 & 0.17 & 0.17 & 0.19 \\
\hline NWS & 200 & -400 & 291 & 0.15 & 0.31 & 0.12 & 0.34 & 0.25 & 0.54 \\
\hline$A E-D$ OSS & 120 & -200 & 27 & 0.29 & 0.10 & 0.23 & 0.09 & 0.36 & 0.16 \\
\hline NNS & 200 & $-\quad 400$ & $2 E$ & -0.05 & 0.23 & -0.10 & 0.25 & 0.52 & 0.38 \\
\hline$A \Xi-\Xi N A C \Xi$ & 120 & -200 & 26 & -0.01 & 0.16 & 0.08 & 0.15 & -0.01 & 0.19 \\
\hline NMS & 200 & -400 & 145 & 0.24 & $0.3 \varepsilon$ & 0.21 & 0.37 & -0.13 & 0.39 \\
\hline & 600 & -800 & 54 & 0.24 & 0.20 & 0.18 & 0.20 & -0.28 & 0.35 \\
\hline ESRO- 5 & 200 & -400 & 231 & 0.08 & 0.33 & 0.07 & 0.36 & 0.26 & 0.50 \\
\hline NMS & & & & & & & & & \\
\hline DE-2 NACS & 200 & -400 & 570 & -0.30 & 0.36 & -0.36 & 0.36 & -0.15 & 0.50 \\
\hline$N M S$ & 400 & -800 & 253 & 0.30 & 1.79 & 0.10 & 1.74 & 1.59 & 2.21 \\
\hline
\end{tabular}

-Entize data set 
Teble $3(c)$. Comparison of models to dacabase on $N_{2}$ concencration across all geomagnetic acrivicy levels

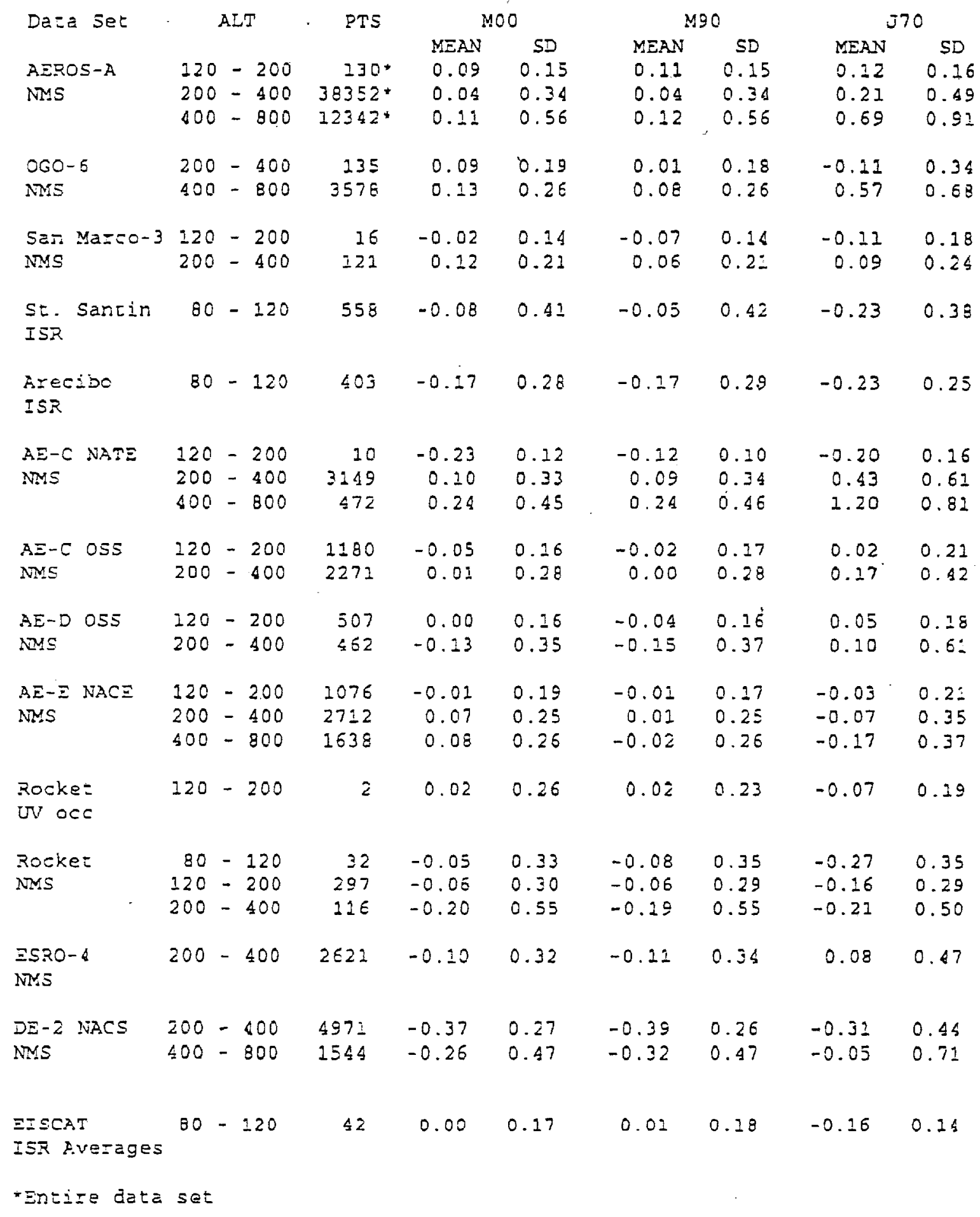


Table 4(a). Comparison of models to darabase on total oxygen concentracion $\left(0+2 \mathrm{O}_{2}\right)$ Eor guiet geomagnetic activity $\left(A_{D} \leq 10\right)$

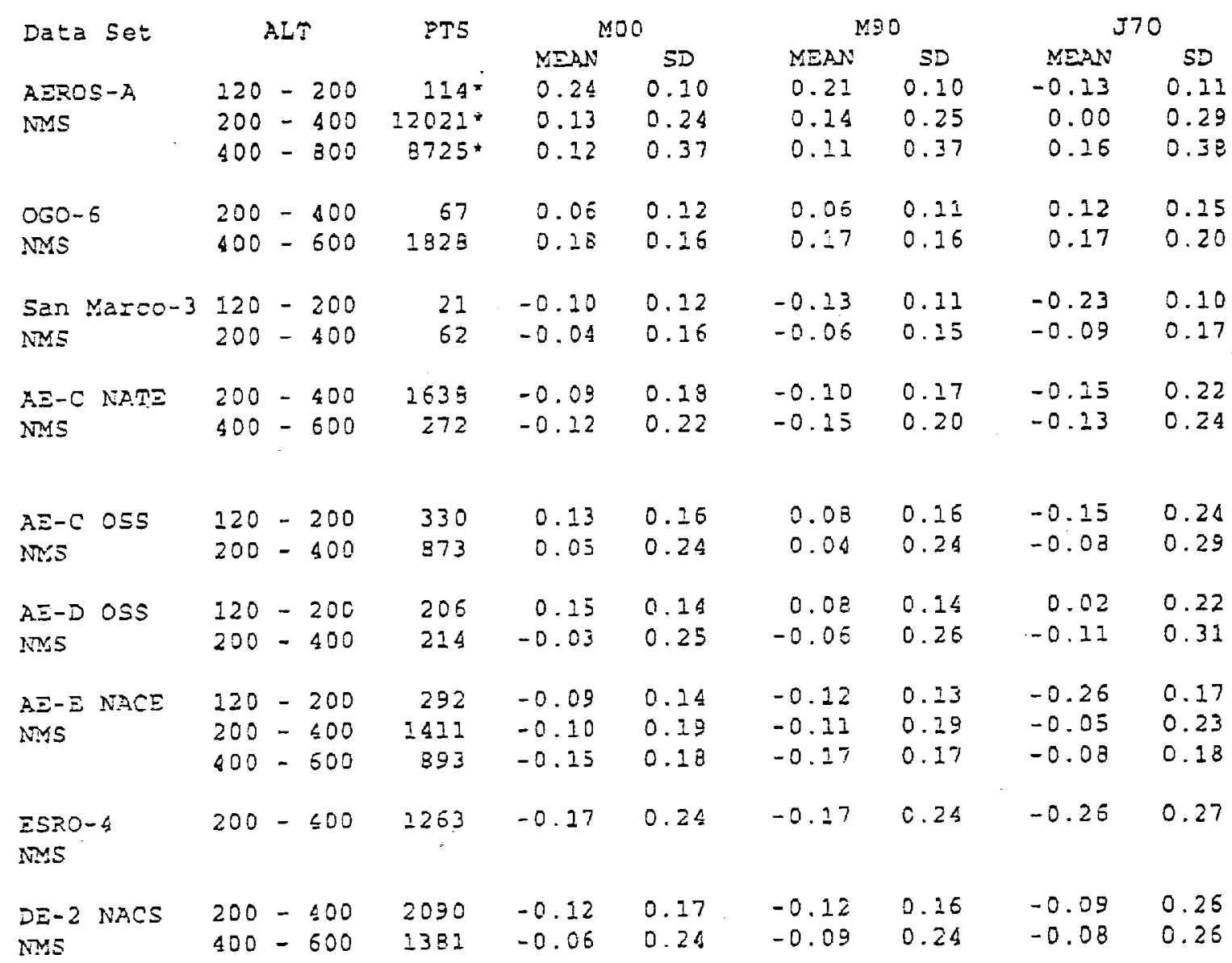

Đreire dara set 
Table $4(b)$. Comparison of models do database on tocal oxygen concentracior. $\left(0+2 \mathrm{O}_{2}\right)$ for high geomagne:ic activity levels $\left(\mathrm{A}_{\mathrm{p}} \geq 50\right)$

\begin{tabular}{|c|c|c|c|c|c|c|c|c|c|}
\hline \multirow{2}{*}{ Deta Set } & \multirow{2}{*}{\multicolumn{2}{|c|}{ ALT }} & \multirow{2}{*}{$9 ? 5$} & \multicolumn{2}{|c|}{ MOO } & \multicolumn{2}{|c|}{ MSO } & \multicolumn{2}{|c|}{$\mathrm{J} 70$} \\
\hline & & & & $M E A N$ & D & MEAN & SD & $M=2 N$ & SD. \\
\hline$A \equiv R O S-A$ & 200 & -400 & $2095 *$ & 0.05 & 0.49 & 0.07 & 0.50 & -0.20 & 0.60 \\
\hline NMS & 400 & -300 & $1558^{\circ}$ & $-0 . i 2$ & 0.50 & -0.08 & 0.51 & -0.13 & 0.55 \\
\hline OGO-E & 200 & -400 & 12 & -0.01 & 0.14 & 0.01 & 0.25 & 0.04 & 0.25 \\
\hline NRS & 800 & & 137 & 0.23 & 0.18 & 0.19 & 0.13 & 0.28 & 0.22 \\
\hline$A \equiv-C$ NATE & 200 & -400 & 203 & -0.05 & 0.32 & -0.05 & 0.32 & -0.19 & 0.41 \\
\hline Mis & 400 & -500 & 13 & -0.26 & 0.16 & -0.29 & 0.13 & -0.25 & 0.17 \\
\hline $\begin{array}{l}A E-C \text { OSS } \\
\text { NMS }\end{array}$ & $\begin{array}{l}120 \\
200\end{array}$ & $\begin{array}{l}-200 \\
-\quad 400\end{array}$ & $\begin{array}{l}142 \\
1 \in 9\end{array}$ & 0.23 & 0.28 & 0.15 & 0.19 & $\begin{array}{l}-0.05 \\
-0.28\end{array}$ & 0.28 \\
\hline & 200 & -400 & $1 \in 9$ & 0.12 & 0.30 & 0.11 & 0.31 & & 0.68 \\
\hline & 200 & -800 & 10 & 0.08 & 0.19. & 0.00 & 0.20 & & \\
\hline $\begin{array}{l}A \equiv-E \text { NACE } \\
N V S\end{array}$ & $\begin{array}{l}120 \\
200\end{array}$ & -200 & 7 & -0.06 & 0.15 & -0.01 & 0.15 & 0.05 & 0.27 \\
\hline NWS & $\begin{array}{l}200 \\
400\end{array}$ & -400 & 133 & -0.04 & 0.32 & -0.04 & 0.32 & 0.08 & 0.43 \\
\hline & 400 & -600 & 40 & -0.10 & 0.20 & -0.12 & 0.20 & 0.01 & 0.21 \\
\hline$\equiv 580-6$ & 200 & $-\triangle 00$ & 231 & -0.11 & 0.23 & -0.11 & 0.23 & -0.29 & 0.38 \\
\hline Nons & & & & & & & & & \\
\hline$D E-2$ NAC5 & 200 & -400 & 563 & -0.16 & 0.23 & -0.16 & 0.24 & -0.29 & 0.39 \\
\hline NMS & 400 & -500 & 389 & -0.08 & 0.25 & -0.03 & 0.27 & -0.25 & 0.39 \\
\hline
\end{tabular}

intire àata set 


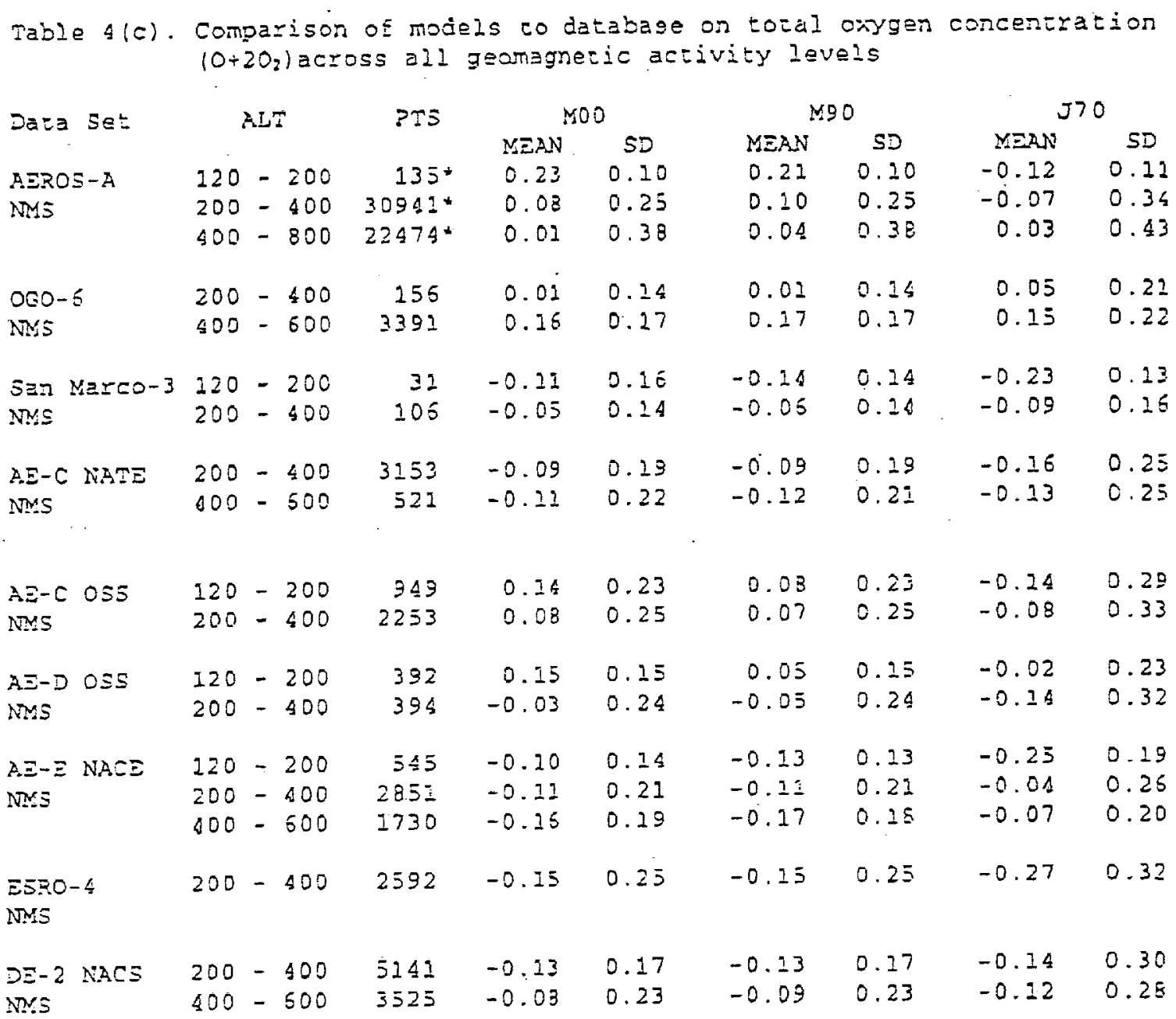

*Encire daza sez 


\begin{tabular}{|c|c|c|c|c|c|c|c|c|c|}
\hline \multirow{3}{*}{$\begin{array}{l}\text { Table } 5(a) \text {. } \\
\text { Daca Set }\end{array}$} & \multicolumn{5}{|c|}{ geomagnetic activicy las } & on heliu & $\operatorname{cosce}$ & zation & EOT \\
\hline & \multirow{2}{*}{\multicolumn{2}{|c|}{ ALT }} & \multirow{2}{*}{ pts } & \multicolumn{2}{|c|}{ MOO } & \multicolumn{2}{|c|}{ MSO } & \multicolumn{2}{|c|}{970} \\
\hline & & & & $M E A N$ & SD & MEAN & SD & MEAN & SD \\
\hline \multirow{3}{*}{$\begin{array}{l}\text { AEROS-A } \\
\text { NMS }\end{array}$} & 120 & -200 & $95^{\circ}$ & 0.71 & 0.32 & 0.74 & 0.32 & -0.45 & 0.3 \\
\hline & 200 & -400 & $11814^{\top}$ & 0.24 & 0.32 & 0.22 & 0.32 & -0.06 & 0.9 \\
\hline & 400 & -800 & 5545 & 0.19 & 0.38 & 0.15 & 0.38 & -0.13 & 0.7 \\
\hline $0 G 0-6$ & 200 & -400 & 35 & 0.20. & 0.25 & 0.18 & 0.15 & 0.25 & 0.3 \\
\hline NMS & 400 & -800 & 2990 & 0.23 & 0.19 & 0.21 & 0.19 & 0.63 & 0.42 \\
\hline Sen Ma $\cos 3$ & 120 & -200 & 13 & 0.45 & 0.27 & 0.42 & 0.28 & 0.06 & 0.15 \\
\hline NMS & 200 & $=400$ & 91 & 0.15 & 0.29 & 0.14 & 0.22 & -0.13 & 0.33 \\
\hline$A \Xi-C$ NATE & 200 & -400 & 1706 & -0.30 & 0.17 & -0.32 & 0.18 & -0.34 & 0.76 \\
\hline NMS & 400 & -800 & 234 & -0.29 & 0.18 & -0.32 & 0.18 & -0.02 & 0.73 \\
\hline \multirow{2}{*}{$\begin{array}{l}A . E=C \text { OSS } \\
\text { NMS }\end{array}$} & 120 & -200 & 339 & -0.09 & 0.27 & -0.08 & $0.2 B$ & -0.54 & 0.75 \\
\hline & 200 & -400 & 829 & 0.07 & 0.22 & 0.04 & 0.21 & -0.29 & 0.92 \\
\hline \multirow{2}{*}{$\begin{array}{l}A \bar{E}-D \text { OSS } \\
\mathrm{NMS}\end{array}$} & 120 & -200 & 192 & -0.09 & 0.27 & -0.12 & 0.27 & -0.19 & 1.22 \\
\hline & 200 & -400 & 227 & -0.23 & 0.38 & -0.26 & 0.37 & -0.24 & 1.25 \\
\hline \multirow{3}{*}{$\begin{array}{l}A E-E N A C E \\
\text { NNS }\end{array}$} & 120 & -200 & 257 & 0.12 & 0.22 & 0.20 & 0.22 & -0.08 & 0.50 \\
\hline & 200 & -400 & 1416 & -0.06 & 0.18 & -0.07 & $0.1 E$ & -0.21 & 0.46 \\
\hline & 400 & -300 & 845 & $-0.0 B$ & 0.19 & -0.10 & 0.20 & -0.14 & 0.43 \\
\hline \multirow{2}{*}{$\begin{array}{l}\text { ESRO-4 } \\
\text { NWS }\end{array}$} & 200 & $-\$ 00$ & 2119 & -0.13 & 0.32 & -0.14 & 0.32 & -0.34 & 1.06 \\
\hline & & & & & & & & & \\
\hline \multirow{3}{*}{$\begin{array}{l}\text { DE-2 NACS } \\
\text { NMS }\end{array}$} & 200 & -400 & 1971 & -0.13 & 0.16 & -0.13 & 0.26 & -0.12 & 0.72 \\
\hline & 400 & -800 & 1364 & -0.12 & 0.16 & -0.14 & 0.16 & -0.25 & 0.56 \\
\hline & 800 & -1200 & 312 & -0.06 & 0.20 & -0.10 & 0.19 & -0.28 & 0.39 \\
\hline
\end{tabular}




\begin{tabular}{|c|c|c|c|c|c|c|c|c|c|}
\hline \multirow[t]{2}{*}{ Data set } & \multicolumn{2}{|c|}{ ALT } & \multirow[t]{2}{*}{ ZTS } & \multicolumn{2}{|c|}{$\mathrm{MOO}$} & \multicolumn{2}{|c|}{ M90 } & \multicolumn{2}{|c|}{570} \\
\hline & & & & MEAN & SD & $M E R N$ & $S D$ & MEAN & SD \\
\hline$A=R O S-\lambda$ & 200 & -400 & $2092^{\circ}$ & 0.31 & 0.95 & 0.28 & 0.95 & -0.11 & 1.15 \\
\hline NMS & 400 & -800 & $1566^{*}$ & 0.26 & 1.00 & 0.25 & 1.00 & -0.18 & 1.11. \\
\hline OGO- 5 & 200 & -400 & 13 & 0.03 & 0.09 & 0.02 & 0.12 & 0.45 & 0.41 \\
\hline NMS & 400 & -800 & 140 & 1.40 & 2.49 & 1.41 & 1.50 & 1.82 & 1.39 \\
\hline AE-C NATE & 200 & $-\$ 00$ & 174 & -0.30 & 0.31 & -0.32 & 0.31 & -0.33 & 0.80 \\
\hline $\mathrm{MMS}$ & 400 & -800 & 13 & -0.30 & 0.23 & -0.35 & 0.22 & 0.12 & 0.54 \\
\hline$A E-C$ OSS & 120 & -200 & 145 & -0.06 & 0.45 & -0.06 & 0.46 & -0.60 & 0.99 \\
\hline MMS & 200 & $-\$ 00$ & 202 & -0.06 & 0.44 & -0.08 & 0.15 & -0.36 & 1.02 \\
\hline$A \equiv-D$ OSS & 120 & -200 & 15 & -0.08 & 0.31 & -0.16 & 0.30 & 0.02 & 0.59 \\
\hline NMS & 200 & $=400$ & 33 & -0.20 & 0.31 & -0.28 & 0.29 & -0.17 & 0.65 \\
\hline$A \equiv-E$ NACE & 120 & -200 & 8 & 0.17 & 0.11 & 0.16 & 0.12 & 0.79 & 0.26 \\
\hline NMS & 200 & -400 & 131 & -0.03 & 0.21 & -0.06 & 0.20 & 0.20 & 0.49 \\
\hline & 400 & -300 & 49 & -0.12 & 0.12 & -0.15 & 0.13 & 0.02 & 0.28 \\
\hline $\begin{array}{l}\text { ESRO- } \\
\text { NMS }\end{array}$ & 200 & -400 & 211 & -0.17 & 0.34 & -0.18 & 0.34 & -0.40 & 0.76 \\
\hline$D \equiv-2$ NACS & 200 & -400 & 496 & -0.16 & 0.26 & -0.17 & 0.26 & -0.40 & 0.58 \\
\hline NMS & 400 & $=800$ & 572 & -0.13 & 0.29 & -0.12 & 0.33 & -0.45 & 0.51 \\
\hline & 800 & -1200 & 46 & -0.17 & 0.17 & -0.19 & 0.18 & -0.50 & $0 . \leqslant 1$ \\
\hline
\end{tabular}

*Entire data sez 


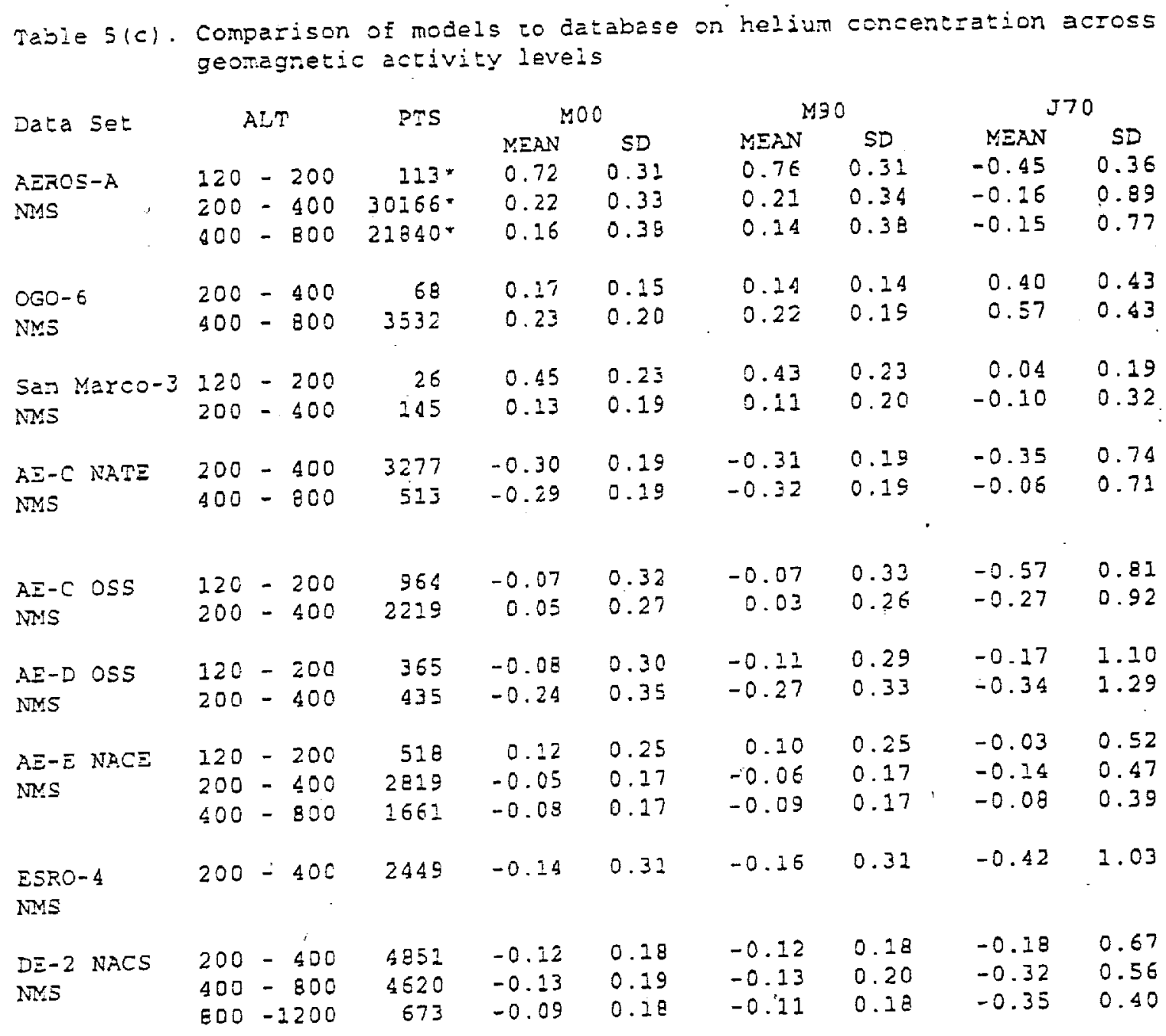

rentire deta set 


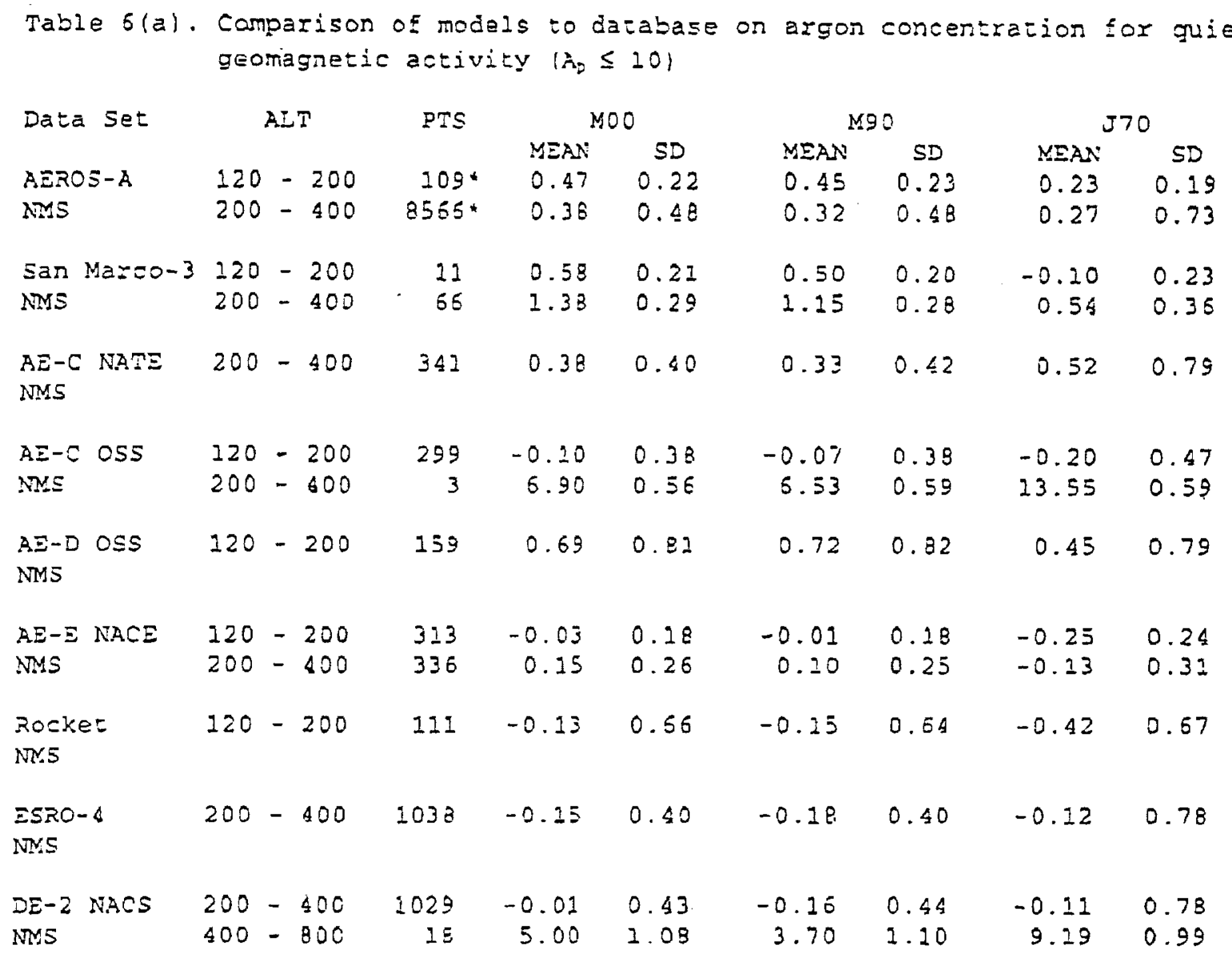

+Entize data sez 


\begin{tabular}{|c|c|c|c|c|c|c|c|c|c|c|}
\hline Data Set & & $A L$ & & PTS & & & & & & \\
\hline $\begin{array}{l}\text { AEROS - A } \\
\text { NMS }\end{array}$ & 200 & - & 400 & 1723 * & $\begin{array}{l}\text { MEAN } \\
0.58\end{array}$ & $\begin{array}{c}5 D \\
1.53\end{array}$ & $\begin{array}{l}M E A N \\
0.57\end{array}$ & $\begin{array}{l}S \bar{D} \\
1.52\end{array}$ & $\begin{array}{l}\text { MEAN } \\
1.12\end{array}$ & $\begin{array}{l}\text { SD } \\
2.81 .\end{array}$ \\
\hline $\begin{array}{l}\text { XI-C NATE } \\
\text { NMS }\end{array}$ & 200 & - & 400 & 47 & 0.54 & 0.41 & $0.5 E$ & 0.42 & 0.12 & 0.67 \\
\hline $\begin{array}{l}\text { AE-C OSS } \\
\text { NMS }\end{array}$ & $\begin{array}{l}120 \\
200\end{array}$ & - & $\begin{array}{l}200 \\
400\end{array}$ & $\begin{array}{r}112 \\
4\end{array}$ & $\begin{array}{l}-0.01 \\
74.95\end{array}$ & $\begin{array}{l}0.50 \\
2.16\end{array}$ & $\begin{array}{r}0.14 \\
69.97\end{array}$ & $\begin{array}{l}0.50 \\
2.01\end{array}$ & $\begin{array}{r}0.43 \\
83.57\end{array}$ & $\begin{array}{l}0.64 \\
1.91\end{array}$ \\
\hline $\begin{array}{l}A \equiv-D \text { OSS } \\
N M S\end{array}$ & 120 & - & 200 & 11 & 4.51 & 1.25 & 4.27 & 1.25 & 3.27 & 1.25 \\
\hline $\begin{array}{l}\text { AE- } \equiv \text { NACE } \\
\text { NMS }\end{array}$ & $\begin{array}{l}120 \\
200\end{array}$ & - & $\begin{array}{l}200 \\
400\end{array}$ & $\begin{array}{l}13 \\
58\end{array}$ & $\begin{array}{r}-0.18 \\
0.55\end{array}$ & $\begin{array}{l}0.13 \\
0.79\end{array}$ & $\begin{array}{r}-0.15 \\
0.58\end{array}$ & $\begin{array}{l}0.12 \\
0.76\end{array}$ & $\begin{array}{l}-0.46 \\
-0.07\end{array}$ & $\begin{array}{l}0.21 \\
0.69\end{array}$ \\
\hline $\begin{array}{l}\text { ESRO-4 } \\
\text { NMS }\end{array}$ & 200 & - & 400 & 223 & -0.06 & 0.50 & -0.07 & 0.59 & 0.55 & 1.07 \\
\hline $\begin{array}{l}\text { DE-2 NACS } \\
\text { NMS }\end{array}$ & $\begin{array}{l}200 \\
400\end{array}$ & - & $\begin{array}{l}400 \\
800\end{array}$ & $\begin{array}{r}455 \\
81\end{array}$ & $\begin{array}{l}0.12 \\
1.28\end{array}$ & $\begin{array}{l}0.73 \\
1.00\end{array}$ & $\begin{array}{r}-0.03 \\
0.45\end{array}$ & $\begin{array}{l}0.76 \\
1.10\end{array}$ & $\begin{array}{r}1.27 \\
12.77\end{array}$ & $\begin{array}{l}1.12 \\
1.22\end{array}$ \\
\hline
\end{tabular}

* Encire data set 


\begin{tabular}{|c|c|c|c|c|c|c|c|c|c|c|}
\hline \multirow{3}{*}{$\begin{array}{l}\text { Table } \sigma(c) \text {. } \\
\text { Data Set }\end{array}$} & \multicolumn{6}{|c|}{$\begin{array}{l}\text { Comparison of models to dacaiase } \\
\text { geomagnetic activity levels }\end{array}$} & \multicolumn{3}{|c|}{ concentration } & $0 x \cos 5$ \\
\hline & & $A:$ & & PRs & \multicolumn{2}{|c|}{ MOO } & \multicolumn{2}{|c|}{ M90 } & \multicolumn{2}{|c|}{$\mathrm{J} 70$} \\
\hline & & & & & MEAN & SD & MEAN & $S D$ & MEAN & SD \\
\hline AEROS-A & 120 & - & 200 & $130^{*}$ & 0.43 & 0.23 & 0.45 & 0.23 & 0.24 & 0.20 \\
\hline NMS & 200 & - & 400 & $22539^{\circ}$ & 0.23 & 0.50 & 0.28 & 0.50 & 0.40 & 0.87 \\
\hline San Mazco-3 & 120 & - & 200 & 22 & 0.53 & 0.19 & 0.51 & 0.18 & -0.04 & 0.23 \\
\hline NMS & 200 & - & 400 & 109 & 1.30 & 0.27 & 1.15 & 0.27 & 0.49 & 0.35 \\
\hline $\begin{array}{l}\text { AE-C NATE } \\
\text { NMS }\end{array}$ & 200 & - & 400 & 896 & 0.51 & 0.37 & 0.51 & 0.39 & 0.78 & 0.85 \\
\hline$A E-C$ OSS & 120 & - & 200 & 802 & -0.03 & 0.43 & 0.00 & 0.44 & -0.02 & 0.59 \\
\hline NMS & 200 & - & 500 & 25 & 2.63 & 2.10 & 2.57 & 2.24 & 3.37 & 2.46 \\
\hline $\begin{array}{l}\text { AE-D OSS } \\
\text { NMS }\end{array}$ & 120 & - & 200 & 287 & 0.56 & 0.77 & 0.61 & 0.78 & 0.40 & 0.79 \\
\hline$A E-E$ NACE & 120 & - & 200 & 546 & -0.02 & 0.25 & -0.05 & 0.25 & -0.28 & 0.29 \\
\hline NMS & 200 & - & 400 & 719 & 0.16 & 0.39 & 0.14 & 0.39 & -0.13 & 0.46 \\
\hline Rocket & 80 & - & 120 & 23 & -0.35 & 0.54 & -0.38 & 0.53 & $-0.5 B$ & 0.52. \\
\hline NMS & $\begin{array}{l}120 \\
200\end{array}$ & - & $\begin{array}{l}200 \\
400\end{array}$ & $\begin{array}{r}168 \\
10\end{array}$ & $\begin{array}{l}-0.14 \\
-0.34\end{array}$ & $\begin{array}{l}0.52 \\
0.02\end{array}$ & $\begin{array}{l}-0.14 \\
-0.27\end{array}$ & $\begin{array}{l}0.49 \\
0.03\end{array}$ & $\begin{array}{r}-0.36 \\
0.05\end{array}$ & $\begin{array}{l}0.55 \\
0.02\end{array}$ \\
\hline $\begin{array}{l}\text { ESRO-4 } \\
\text { NNS }\end{array}$ & 200 & - & 600 & 2351 & -0.19 & 0.44 & -0.19 & 0.44 & 0.00 & 0.39 \\
\hline $\begin{array}{l}D E-2 \text { NACS } \\
\text { NMS }\end{array}$ & 200 & - & 400 & 3045 & -0.05 & 0.52 & -0.15 & 0.53 & 0.23 & 0.96 \\
\hline NMS & 400 & - & 300 & 170 & 1.22 & 1.01 & 0.64 & 1.10 & 8.32 & 1.17 \\
\hline
\end{tabular}

*arcire data set 


\begin{tabular}{|c|c|c|c|c|c|c|c|c|c|}
\hline \multirow[t]{2}{*}{ Data Set } & \multirow{2}{*}{\multicolumn{2}{|c|}{$A L T$}} & \multirow[t]{2}{*}{ PTS } & \multicolumn{2}{|c|}{ MOO } & \multicolumn{2}{|c|}{ M90 } & \multicolumn{2}{|c|}{370} \\
\hline & & & & $M \equiv A N$ & SD & MEAN & SD & MEAN & $S D$ \\
\hline$S M N^{2}$ & 120 & -200 & $42794^{\ddagger}$ & -0.13 & 0.37 & -0.40 & 0.37 & -0.63 & 0.41 \\
\hline \multirow[t]{2}{*}{ UN oce } & 120 & -200 & 925 & -0.08 & 0.25 & -0.37 & 0.29 & -0.66 & 0.35 \\
\hline & 200 & -100 & $13043^{\circ}$ & -0.23 & 0.62 & -0.47 & 0.71 & -0.63 & 0.78 \\
\hline$A E-C$ OSS & 120 & -200 & 60 & -0.02 & 0.22 & -0.10 & 0.24 & -0.29 & 0.23 \\
\hline NMS & 200 & -400 & 23 & 0.07 & 0.42 & 0.00 & 0.38 & -0.12 & 0.43 \\
\hline$A \equiv-D$ OSS & 120 & -200 & 219 & 0.26 & 0.34 & 0.19 & 0.34 & 0.01 & 0.36 \\
\hline NMS & 200 & -400 & 71 & 0.11 & c. 36 & 0.15 & 0.36 & 0.05 & 0.42 \\
\hline$A E-E$ OSS & 120 & -200 & 122 & 0.24 & 0.22 & 0.18 & 0.22 & -0.12 & 0.25 \\
\hline NMS & 200 & -400 & 11 & 0.21 & 0.26 & 0.22 & 0.26 & -0.06 & 0.28 \\
\hline $\begin{array}{l}\text { Rocket } \\
\text { Aoso=ption }\end{array}$ & 120 & -200 & 11 & -0.12 & 0.30 & $-0.1 E$ & 0.26 & -0.41 & 0.32 \\
\hline Rocket & 120 & -200 & 211 & 0.12 & 0.35 & -0.02 & 0.32 & -0.39 & 0.34 \\
\hline NMS & 200 & $-\$ 00$ & 29 & -0.13 & 0.57 & -0.27 & 0.47 & -0.55 & 0.31 \\
\hline$x \equiv-C$ EUVS & & 100 & 47 & -0.09 & 0.22 & -0.05 & 0.23 & -0.20 & 0.26 \\
\hline UV occ & & 130 & 20 & 0.26 & 0.19 & 0.27 & 0.20 & -0.16 & 0.21 \\
\hline & & 150 & 61 & 0.19 & 0.23 & 0.08 & 0.28 & -0.23 & 0.31 \\
\hline$A E-\bar{\Xi}$ EUVS & & 100 & 114 & 0.03 & 0.33 & -0.02 & 0.34 & -0.06 & 0.32 \\
\hline ir Occ & & 130 & 77 & 0.01 & 0.19 & -0.03 & 0.18 & -0.43 & 0.21 \\
\hline & & $150^{2}$ & 72 & -0.21 & 0.18 & -0.33 & 0.27 & -0.56 & 0.24 \\
\hline & & $150^{2}$ & 152 & -0.05 & 0.20 & -0.19 & 0.19 & -0.47 & 0.25 \\
\hline
\end{tabular}

Enlirc data sel; rows not marked relate to the subsel of data selecled lo generale model.

Solar Maximum Mission

Channel 19

Channel 06 


\begin{tabular}{|c|c|c|c|c|c|c|c|c|c|}
\hline \multirow[t]{2}{*}{ Daca Set } & \multirow{2}{*}{\multicolumn{2}{|c|}{$A L T$}} & \multirow[t]{2}{*}{ PTS } & \multicolumn{2}{|c|}{ MOO } & \multicolumn{2}{|c|}{ M90 } & \multicolumn{2}{|c|}{570} \\
\hline & & & & NEAN & SD & $M E A N$ & $S D$ & MEAN & SD \\
\hline $\sin { }^{1}$ & 120 & -200 & $\$ 136^{7}$ & -0.25 & 0.55 & -0.49 & 0.61 & -0.69 & 0.65 \\
\hline \multirow[t]{2}{*}{ UV $0=c$} & 220 & -200 & 183 & -0.12 & 0.34 & -0.48 & 0.46 & -0.67 & 0.56 \\
\hline & 200 & -400 & $1780^{\circ}$ & -0.82 & 3.77 & -0.38 & 3.63 & -0.92 & 3.85 \\
\hline$A E-C$ OSS & 120 & -200 & 2 & 0.32 & 0.23 & 0.23 & 0.20 & 0.42 & 0.09 \\
\hline NMS & 200 & $=100$ & 1 & 1.28 & 0.00 & 1.00 & 0.00 & 0.70 & 0.00 \\
\hline$A \equiv-C$ EUVS & & 100 & 8 & 0.08 & 0.22 & 0.08 & 0.20 & -0.26 & 0.15 \\
\hline \multirow[t]{2}{*}{ UV OCc } & & 130 & 1 & 0.25 & 0.00 & 0.19 & 0.00 & 0.00 & 0.00 \\
\hline & & 150 & 7 & 0.32 & 0.39 & 0.11 & 0.39 & 0.27 & 0.38 \\
\hline$A \equiv-\Xi$ EUNS & & 200 & $\varepsilon$ & 0.22 & 0.19 & 0.07 & 0.24 & -0.05 & 0.12 \\
\hline \multirow[t]{3}{*}{ UN oec } & & 130 & a & 0.09 & 0.15 & 0.01 & 0.16 & -0.45 & 0.21 \\
\hline & & $\begin{array}{l}150^{2} \\
150^{3}\end{array}$ & 5 & 0.84 & 1.61 & 0.44 & 1.67 & -0.19 & 1.53 \\
\hline & & $1=0^{\circ}$ & 15 & -0.04 & 0.29 & -0.21 & 0.30 & -0.53 & 0.35 \\
\hline
\end{tabular}

\footnotetext{
Entire data set; rows nol marked relale to the subset of data selected to generate model.

Solar Maximum Mission

${ }^{2}$ Channel 19

${ }^{3}$ Channel 05
} 


\begin{tabular}{|c|c|c|c|c|c|c|c|c|c|}
\hline \multirow[t]{2}{*}{ Data set } & \multirow{2}{*}{\multicolumn{2}{|c|}{$A I T$}} & \multirow[t]{2}{*}{ PTS } & \multicolumn{2}{|c|}{ NoO } & \multicolumn{2}{|c|}{ M90 } & \multicolumn{2}{|c|}{$\mathrm{J} 70$} \\
\hline & & & & $M \equiv A N$ & SD & $M \Xi A N$ & $S D$ & $M E R N$ & SD \\
\hline \multirow{3}{*}{$\begin{array}{l}\text { SMM" } \\
\text { UV acc }\end{array}$} & 120 & -200 & $51886^{4}$ & -0.19 & 0.37 & -0.42 & 0.40 & -0.59 & 0.44 \\
\hline & 120 & -200 & 2091 & -0.09 & 0.27 & -0.38 & 0.32 & -0.66 & 0.39 \\
\hline & 200 & -400 & $27225^{t}$ & -0.25 & 0.61 & -0.52 & 0.72 & -0.72 & 0.80 \\
\hline AEE-C OSS & 120 & -200 & 160 & 0.07 & 0.28 & -0.02 & 0.28 & -0.13 & 0.36 \\
\hline NNS & 200 & -400 & 66 & 0.14 & 0.39 & 0.00 & 0.37 & 0.03 & 0.48 \\
\hline$A \equiv-D$ OSS & 120 & -200 & 375 & 0.24 & 0.34 & 0.19 & 0.34 & 0.05 & 0.35 \\
\hline NMS & 200 & $-\leq 00$ & 133 & 0.12 & 0.32 & 0.13 & $0.3 \pm$ & 0.16 & 0.45 \\
\hline$A \equiv-E$ OSS & 120 & -200 & 256 & 0.25 & 0.22 & 0.22 & 0.22 & -0.11 & 0.25 \\
\hline NMS & 200 & -400 & 47 & 0.15 & 0.29 & 0.15 & 0.29 & -0.16 & 0.32 \\
\hline $\begin{array}{l}\text { Rocket } \\
\text { Absorption }\end{array}$ & 120 & -200 & 14 & -0.07 & 0.30 & -0.12 & Absorption & -0.38 & 0.32 \\
\hline Rocket & 30 & -120 & 37 & -0.17 & 0.15 & -0.22 & 0.45 & -0.44 & 0.51 \\
\hline \multirow[t]{2}{*}{ NMS } & 120 & -200 & 295 & 0.09 & 0.34 & -0.04 & 0.31 & -0.38 & 0.33 \\
\hline & 200 & -400 & 44 & -0.19 & 0.55 & -0.31 & 0.45 & -0.55 & 0.42 \\
\hline \multirow{3}{*}{$\begin{array}{l}A \equiv-C \text { EUNS } \\
\text { UN DCS }\end{array}$} & \multicolumn{2}{|r|}{100} & 122 & 0.00 & 0.23 & 0.04 & 0.24 & -0.16 & 0.25 \\
\hline & \multicolumn{2}{|r|}{130} & 54 & 0.25 & 0.21 & 0.26 & 0.21 & -0.09 & 0.24 \\
\hline & \multicolumn{2}{|r|}{150} & 130 & 0.19 & 0.31 & 0.07 & $0.3 i$ & -0.15 & 0.38 \\
\hline \multirow{4}{*}{$\begin{array}{l}A E-E \text { EUVS } \\
\text { UV OCC }\end{array}$} & \multicolumn{2}{|r|}{100} & 249 & 0.08 & 0.30 & 0.03 & 0.31 & -0.05 & 0.29 \\
\hline & \multirow{2}{*}{\multicolumn{2}{|c|}{$\begin{array}{l}130 \\
150^{2}\end{array}$}} & 175 & 0.00 & 0.20 & -0.03 & 0.19 & -0.43 & 0.22 \\
\hline & & & 163 & -0.18 & 0.20 & -0.32 & 0.29 & -0.56 & 0.29 \\
\hline & \multicolumn{2}{|r|}{$150^{3}$} & 300 & -0.05 & 0.21 & -0.78 & 0.20 & -0.48 & 0.27 \\
\hline
\end{tabular}

"Entire dala sel; rows nor marked relare 10 the subset of dala seiected lo generale modal.

I Solar Maximum Mission

${ }^{2}$ Channel 19

Channel 06 
Table $8(a)$. Comparison of models to database on atomic nitrogen concentzation for quier geomagnecic activity levels $\left(n_{0} \leq 10\right)$ *

\begin{tabular}{|c|c|c|c|c|c|c|c|c|c|c|}
\hline \multirow[t]{2}{*}{ Data } & \multirow[t]{2}{*}{ Set } & \multirow{2}{*}{\multicolumn{2}{|c|}{ A.LT }} & \multirow[t]{2}{*}{ 3IS } & \multicolumn{2}{|c|}{1900} & \multicolumn{2}{|c|}{ M90 } & \multicolumn{2}{|c|}{570} \\
\hline & & & & & MEAN & $S D$ & $M=A N$ & SD & NEAN & SD \\
\hline$A E-C$ & ass & 200 & -400 & 380 & -0.11 & 0.44 & 0.11 & $0 . \$ A$ & & \\
\hline NMS & & 400 & -800 & 1994 & -0.05 & 0.30 & 0.19 & 0.31 & & \\
\hline$A E-D$ & oss & 200 & -400 & 2160 & -0.42 & 0.29 & -0.29 & 0.30 & & \\
\hline NMS & & 500 & -800 & 871 & -0.33 & $0: 35$ & -0.16 & $0.3 E$ & & \\
\hline $\begin{array}{l}\text { AE- } \\
\text { NMS }\end{array}$ & oss & 200 & $-\$ 00$ & 3998 & 0.04 & 0.27 & 0.12 & 0.27 & & \\
\hline$D \bar{E}-2$ & NACS & 200 & -400 & 169 & -0.75 & 0.72 & -0.73 & 0.68 & & \\
\hline NMS & & 400 & -800 & 74 & -0.62 & 0.50 & -0.59 & 0.47 & & \\
\hline
\end{tabular}

* Jacchia-70 model does not cover atomic nicrogen 
Table $g(b)$. Comparison of models to databage on azomic nitrogen concentration tor hish geomagnetic activicy $\left(A_{0} \geq 50\right)^{*}$

\begin{tabular}{|c|c|c|c|c|c|c|c|c|c|c|}
\hline \multirow[t]{2}{*}{ Data } & \multirow[t]{2}{*}{ Se: } & \multirow{2}{*}{\multicolumn{2}{|c|}{ AL: }} & \multirow[t]{2}{*}{ PTS } & \multicolumn{2}{|c|}{ MOO } & \multicolumn{2}{|c|}{ M9O } & \multicolumn{2}{|c|}{570} \\
\hline & & & & & MENN & SD & $M \equiv A N$ & SD & MEAN & SD \\
\hline$A \bar{E}-C$ & $0 \leq 5$ & 200 & $-\leqslant 00$ & 21 & -0.15 & 0.38 & -0.02 & 0.40 & & \\
\hline NMS & & 400 & -300 & 335 & 0.00 & 0.38 & 0.18 & 0.40 & & \\
\hline$D E-2$ & NACS & 200 & -400 & 54 & -0.73 & 1.13 & -0.69 & 1.08 & & \\
\hline $\mathrm{MMS}$ & & 400 & -800 & 26 & -0.07 & 1.27 & -0.06 & 2.19 & & \\
\hline
\end{tabular}

* Jacchia-70 mojel does not cover atomic nitrogen 
Table $8(C)$. Comparison of models co database on atomic nitzogen concentration across all geomagneis ectivity levels.

\begin{tabular}{|c|c|c|c|c|c|c|c|c|c|c|}
\hline \multirow[t]{2}{*}{ Data } & \multirow[t]{2}{*}{ Set } & \multirow{2}{*}{\multicolumn{2}{|c|}{ ALT }} & \multirow[t]{2}{*}{ PTS } & \multicolumn{2}{|c|}{ MOO } & \multicolumn{2}{|c|}{$M 90$} & \multicolumn{2}{|c|}{370} \\
\hline & & & & & MEAN & $S D$ & MEAN & $\subseteq D$ & $M E A N$ & $S D$ \\
\hline$A E-C$ & oss & 120 & -200 & 2 & -0.96 & 0.26 & -0.96 & 0.29 & & \\
\hline NMS & & 200 & -400 & 670 & -0.12 & 0.41 & 0.09 & 0.42 & & \\
\hline & & 400 & -800 & 4538 & -0.07 & 0.32 & 0.17 & 0.33 & & \\
\hline$A E-D$ & oss & 200 & -400 & 3844 & -0.12 & 0.31 & $-0.2 \mathrm{~B}$ & 0.31 & & \\
\hline NMS & & 400 & -800 & 1659 & -0.37 & 0.39 & -0.19 & 0.39 & & \\
\hline $\begin{array}{l}\text { A.E-E } \\
\text { NMS }\end{array}$ & oss & 200 & -400 & 7125 & 0.16 & 0.30 & 0.23 & 0.30 & & \\
\hline$D \Xi-2$ & NACS & 120 & -200 & 103 & -0.44 & 0.63 & -0.38 & 0.63 & & \\
\hline NNES & & 200 & -400 & 903 & -0.61 & 0.81 & -0.59 & 0.79 & & \\
\hline & & 400 & -800 & 258 & $-0: 46$ & 0.73 & $=0.44$ & 0.70 & & \\
\hline
\end{tabular}

- Jacchie-70 model does not cover atomic nitroger. 
Table $3(\exists)$. Comparison of models to database on atomic hyarogen concentration for quier geomagneric activity levelg ( $\left.A_{2} \leq 10\right)$ *

\begin{tabular}{|c|c|c|c|c|c|c|c|c|}
\hline \multirow[t]{2}{*}{ Daza } & \multirow[t]{2}{*}{ Set } & \multirow{2}{*}{\multicolumn{2}{|c|}{$A I T$}} & \multirow[t]{2}{*}{ PTE } & \multicolumn{2}{|c|}{ MOO } & \multicolumn{2}{|c|}{ N9D } \\
\hline & & & & & $M E A N$ & SD & MEAN & 50 \\
\hline$A \equiv-C$ & BIMS & 200 & -400 & 1756 & 0.03 & 0.30 & 0.05 & 0.31 \\
\hline INS & & 400 & -800 & 466 & 0.06 & 0.40 & 0.08 & 0.4 .1 \\
\hline$A E-E$ & BIMS & 120 & -200 & 9 & 2.78 & 0.11 & 2.93 & 0.12 \\
\hline INS & & 200 & -400 & 1113 & 0.02 & 0.28 & 0.00 & 0.27 \\
\hline & & 400 & -800 & 516 & -0.02 & 0.31 & -0.05 & 0.32 \\
\hline
\end{tabular}

* Jacchia-70 model does not cover a:omic bydrogen 
Table $9(b)$. Comparison of models to database on acomic hydrogen concentracion for high geomagnetic activity levels $\left(A_{p} \geq 50\right)$.

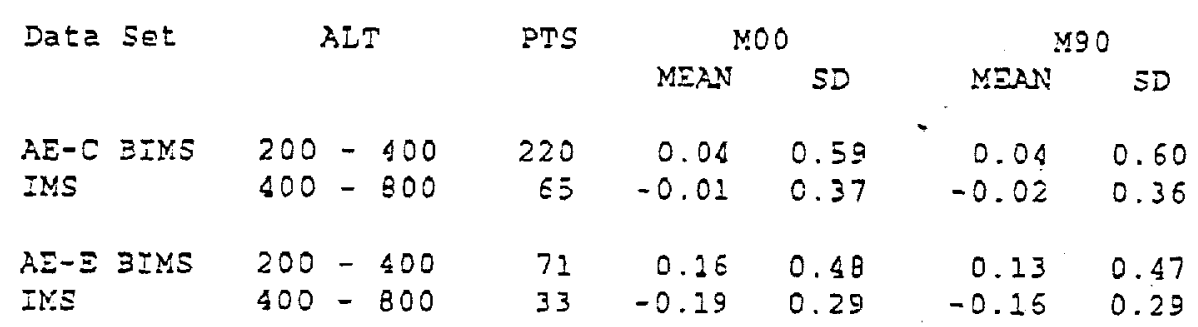

+' Iacciria-70 model does, nor cover atomic hydzogen 
Table $9(c)$. Comparison of models to database on azomic hycrogen concentrazion across all geomagnetic activity levels*

\begin{tabular}{|c|c|c|c|c|c|c|c|c|}
\hline \multirow[t]{2}{*}{ Daこa } & \multirow[t]{2}{*}{ Set } & \multirow{2}{*}{\multicolumn{2}{|c|}{$A L T$}} & \multirow{2}{*}{ PTS } & \multicolumn{2}{|c|}{ MOD } & \multicolumn{2}{|c|}{ M9O } \\
\hline & & & & & NEAN & $\leq D$ & MEAN & $S D$ \\
\hline$A \equiv-C$ & 3IMS & 200 & -400 & 3735 & 0.08 & 0.32 & 0.07 & 0.33 \\
\hline$I N 5$ & & 400 & -200 & $9<2$ & 0.03 & 0.38 & 0.03 & $0.3 \mathrm{~B}$ \\
\hline$A \equiv-\Xi$ & 3IMS & 120 & -200 & 16 & 2.10 & 0.31 & 2.24 & 0.31 \\
\hline IMS & & 200 & -400 & 2275 & 0.01 & 0.30 & -0.01 & 0.30 \\
\hline & & 400 & -800 & 1084 & -0.11 & 0.34 & -0.07 & 0.35 \\
\hline
\end{tabular}

* Jacchia-70 model does nor cover atoric hydrogen 


\title{
POPULAR SUMMARY
}

\begin{abstract}
A new global, upper-atmospheric model is presented. This model is intended to replace previous models utilized in such applications as satellite orbit prediction. The new model termed the NRLMSISE-00 model, together with an associated database, NRLMSIS, is based on total mass densities from satellite accelerometers, satellite orbits, temperature determined by incoherent scatter, and molecular oxygen densities from the SMM solar occultation experiment. Extensive comparison is made with earlier upper atmospheric models such as MSIS and Jacchia-70. Model dependence on solar and geomagnetic activity is demonstrated more clearly than previous models. This model should become the standard for use in satellite orbit prediction.
\end{abstract}

